\title{
Energetic electron precipitation during sawtooth injections
}

\author{
A. J. Kavanagh ${ }^{1, *}$, G. Lu ${ }^{1}$, E. F. Donovan ${ }^{2}$, G. D. Reeves $^{3}$, F. Honary ${ }^{4}$, J. Manninen ${ }^{5}$, and T. J. Immel ${ }^{6}$ \\ ${ }^{1}$ High Altitude Observatory (HAO), National Center for Atmospheric Research (NCAR), P.O. Box 3000, Boulder, CO, \\ 80307-3000, USA \\ ${ }^{2}$ University of Calgary, 2500 University Drive NW, Calgary, Alberta, Canada \\ ${ }^{3}$ Los Alamos National Laboratory, Los Alamos, New Mexico, USA \\ ${ }^{4}$ Department of Communication Systems, Lancaster University, Lancaster, UK \\ ${ }^{5}$ Sodankylä Geophysical Observatory, Tähteläntie 62, 99600 Sodankylä, Finland \\ ${ }^{6}$ University of California at Berkeley, Space Science Lab, Berkeley, CA 94720, USA \\ *now at: Department of Communication Systems, Lancaster University, Lancaster, UK
}

Received: 24 January 2007 - Revised: 3 May 2007 - Accepted: 21 May 2007 - Published: 4 June 2007

\begin{abstract}
We present simultaneous riometer observations of cosmic noise absorption in the nightside and dawn-noon sectors during sawtooth particle injections during 18 April 2002. Energetic electron precipitation $(>30 \mathrm{keV})$ is a feature of magnetospheric substorms and cosmic radio noise absorption acts as a proxy for qualitatively measuring this precipitation. This event provides an opportunity to compare the absorption that accompanies periodic electron injections with the accepted paradigm of substorm-related absorption. We consider whether the absorption is consistent with the premise that these injections are quasi-periodic substorms and study the effects of sustained activity on the level of precipitation. Four consecutive electron injection events have been identified from the LANL (Los Alamos National Laboratory) geosynchronous data; the first two showing that additional activity can occur within the $2-4 \mathrm{~h}$ sawtooth periodicity. The first three events have accompanying absorption on the nightside that demonstrate good agreement with the expected pattern of substorm-absorption: discrete spike events with poleward motion at the onset followed by equatorward moving structures and more diffuse absorption, correlated with optical observations. Dayside absorption is linked to gradient-curvature drifting electrons observed at geostationary orbit and it is shown that low fluxes can lead to a lack of absorption as precipitation is suppressed; precipitation begins when the drifting electron flux surpasses some critical level following continuous injections of electrons from the magnetotail. In addition it is shown that the apparent motion of absorption determined from an azimuthal chain of riometers exhibits an acceleration that may be indicative of an energisation of the drifting electron population.
\end{abstract}

Correspondence to: A. J. Kavanagh

(a.j.kavanagh@lancs.ac.uk)
Keywords. Ionosphere (Auroral ionosphere) - Magnetospheric physics (Energetic particles, precipitating; Storms and substorms)

\section{Introduction}

During some geomagnetic storms geosynchronous satellites observe quasi-periodic changes in energetic particle fluxes (particularly protons but also electrons); these take the form of sharp increases followed by gradual decays observed across large local time ranges. The overall profile is a well defined "sawtooth" composed of particle injections occurring every 2-4h (e.g. Borovsky et al., 2001; Henderson et al., 2002; Skoug et al., 2002; Huang et al., 2003a). These variations occur at the same time as increased emissions from energetic neutral atoms in the inner magnetosphere, confirming the sawtooth signature as multiple ion and electron injections (Reeves et al., 2003) rather than some local effect at the satellite. The sawtooth is associated with stretching and dipolarisation of the magnetic field and displays similar characteristics to periodic substorms (e.g. Borovsky et al., 1993; Belian et al., 1995) and in the past individual teeth have been studied as substorms (Henderson, 2004). Huang et al. (2003a) used observations from three geomagnetic storms to show that continuous energy transfer to the magnetosphere is necessary to maintain sawtooth behaviour. They suggested that solar wind pressure oscillations excite a magnetospheric resonant state, which triggers substorms at the resonant frequency without the need for subsequent external triggers.

A number of authors have used riometer (Little and lienbach, 1959) chains to provide a global picture of energetic electron precipitation related to substorms (Hargreaves et al.,

Published by Copernicus GmbH on behalf of the European Geosciences Union. 
1975, 1997, 2001; Pytte el al., 1976; Ranta et al., 1981; Ranta et al., 1999). Riometers provide a simple means of monitoring the precipitation of energetic electrons (energy greater than $\sim 30 \mathrm{keV}$ ) via measurements of the cosmic radio noise absorption (CNA), which has been recognised as a substorm phenomenon (Akasofu, 1968). CNA manifests in various time-dependent structures during the phases of a substorm both on the night and dayside. During the growth phase an equatorward drifting arc forms (Hargreaves et al., 1975; Ranta et al., 1981); this can contain pulsating forms (Ranta et al., 1999) and is linked to optical arcs (e.g. Jussila et al., 2004). At the expansion phase onset the region of CNA expands both poleward and equatorward, usually in the close to but pre-midnight sector. The change in propagation character occurs close to $\sim 65^{\circ}$ magnetic latitude (Jelly, 1970). The poleward propagating CNA front tends to be a sharp enhancement whilst appearing more gradual at lower latitudes. Following onset the riometer absorption is usually highly correlated with near-equatorial $>30 \mathrm{keV}$ electron flux (Baker et al., 1981) indicating that the CNA is a result of strong pitch angle diffusion in the electron population that is freshly injected from the magnetotail.

Small scale structure also appears following the onset of the expansion phase, particularly the spike-event. Lasting 1$2 \mathrm{~min}$ in duration spikes appear at the poleward edge of the surge and were thought to be caused by the motion of an elongated $10-50 \mathrm{~km}$ thick ribbon of absorption (e.g. Neilsen and Axford, 1977). Observations with imaging riometers have shown that the spike event is actually localised in nature with typical dimensions of $190 \times 80(167 \times 74) \mathrm{km}$ at $\mathrm{L} \sim 6$ $(\sim 13)$ (Hargreaves et al., 1997). The spikes typically display a poleward motion at the start of an event with speeds from hundreds to thousands of $\mathrm{ms}^{-1}$. There is also usually an associated east or westward motion, the latter being more prevalent (Spanswick et al., 2005). Stauning (1996) identified a number (6-8 per hour) of localised discrete events which included some equatorward moving forms. The spike event also displays fine structure similar to magnetic Pi pulsations suggesting a common source region for the modulation (e.g. Hargreaves et al., 2001; Aminaei et al., 2006).

As well as the north and southward motion the background CNA displays azimuthal propagation (e.g. Hargreaves, 1968). It is probable that this is linked with the motion of the injection region, but also the electrons will gradient-curvature drift eastward towards dawn (e.g. Kavanagh et al., 2002, and references therein). The electrons are quasi-trapped and experience pitch-angle scattering through whistler mode wave interactions (e.g. Kennel and Petschek, 1966) such that post midnight the CNA tends to be more diffuse and is less well correlated with optical measurements (e.g. Ansari, 1964). The eastward drift results in a day-side signature that has been termed slowly varying absorption (e.g. Hargreaves and Berry, 1976; Hargreaves and Devlin, 1990; Stauning, 1996; Nishino et al., 1999); however the slow-varying nature is often replaced by small scale spatial and temporal changes including quasi-periodicities of 10 s of minutes and occasionally displays modulation from geomagnetic pulsations such as field line resonances (e.g. Senior and Honary, 2003, and references therein).

A sawtooth event occurred on 18 April 2002; these injections have previously been presented by a number of authors (e.g. Huang et al., 2003b; Lui et al., 2004; Clauer et al., 2006; Henderson et al., 2006) and have been identified as periodic substorms (mean recurrence time $=2.7 \mathrm{~h}$ ), with accompanying phenomena in the magnetotail, inner magnetosphere and in ground magnetometer data. This study focuses on the energetic precipitation signature and considers the data in the context of past riometer observations of substorms. An overview of the whole event is provided with particular consideration of three of the identified "teeth". Observations of CNA show overall agreement with the recognised features of substorm absorption though some unusual effects are highlighted and explained in terms of the effects of sustained geomagnetic activity on the electron population.

\section{Instrumentation}

Observations of the precipitation of energetic electrons during this sawtooth event have been provided by selected stations of the Global Riometer Array (GLORIA) in Canada and Finland. Riometers measure the absorption of cosmic radio noise produced by increased electron concentration in the $\mathrm{D}$ region of the ionosphere, caused by precipitating electrons with energy in excess of about $30 \mathrm{keV}$. Since these instruments only observe the height-integrated absorption no direct information on the precipitation spectrum can be ascertained, and consequently the riometers give only a qualitative measure of the level of precipitation. Figure 1a shows the geographic locations of the riometers used in this study. Canadian data is supplied from what was the CANOPUS project (Rostocker et al., 1995); each of the stations is equipped with a broad beam $\left(\sim 60^{\circ}\right), 30 \mathrm{MHz}$ riometer (pointing to the zenith) as well as a 3-component fluxgate magnetometer, which provide data at $5 \mathrm{~s}$ resolution. The riometer data from Finland have been supplied by a chain of widebeam riometers, operated by Sodankylä Geophysical Observatory (SGO), and from a widebeam instrument co-located with the Imaging Riometer for Ionospheric Studies (IRIS), operated by Lancaster University (UK) (Browne et al., 1995). IRIS data is taken at 1-s resolution but has been averaged to $5 \mathrm{~s}$ here and the SGO chain provides data at 1-min resolution. The data from those riometers that do not operate at $30 \mathrm{MHz}$ have been corrected using the simplified assumption that the CNA is inversely proportional to the square of the operating frequency (e.g. Hargreaves, 1969). Table 1 provides a complete list of the riometers stations and their AACGM (altitude adjusted corrected geomagnetic) coordinates (Baker and Wing, 1989). The two sets of riometers are separated by approximately $9 \mathrm{~h}$ of magnetic local time (MLT) with the 
(a) Geographic Locations of riometers in Canda and FInland

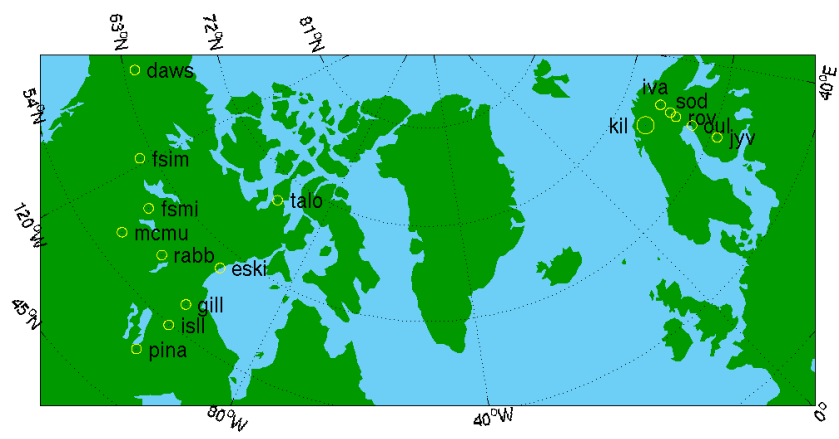

(b) Instrument Positions at 12:00 UT 18 April 2002

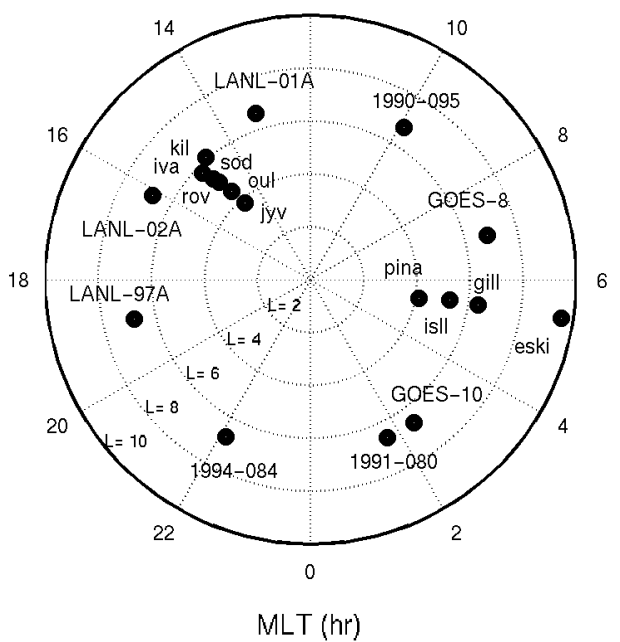

Fig. 1. (a) Positions of the ground stations used in this study. The size of the circles represents approximate fields of view at $90 \mathrm{~km}$ altitude. (b) Orbital positions of the satellites at the magnetospheric equatorial plane, also shown are the projected positions of the SGO and Churchill line riometers using the IGRF model. Taloyaok is not plotted since the riometer is inside the polar cap and exposed to open field lines.

Table 1. List of riometers used in this study. Columns from left to right represent: the instrument name and the chain it belongs to (e.g. $\mathrm{CAN}=\mathrm{CANOPUS}$ ) instrument code, the magnetic coordinates (latitude and longitude), $\mathrm{L}$ shell and the operating frequency. All instruments are in the Northern Hemisphere.

\begin{tabular}{lllll}
\hline Riometer (chain) & Code & $\begin{array}{l}\text { Magnetic Coordinates } \\
\text { (lat, longitude) }\end{array}$ & $\begin{array}{l}\text { L-shell } \\
\text { (Earth Radii) }\end{array}$ & Frequency (MHz) \\
\hline Dawson (CAN) & daws & $66.10^{\circ}, 272.6^{\circ}$ & 6.09 & 30 \\
Eskimo Point (CAN) & eski & $71.12^{\circ}, 332.0^{\circ}$ & 9.55 & 30 \\
Fort McMurray (CAN) & mcmu & $64.64^{\circ}, 308.0^{\circ}$ & 5.45 & 30 \\
Fort Simpson (CAN) & fsim & $67.57^{\circ}, 292.9^{\circ}$ & 6.87 & 30 \\
Fort Smith (CAN) & fsmi & $67.72^{\circ}, 303.6^{\circ}$ & 6.96 & 30 \\
Gillam (CAN) & gill & $66.65^{\circ}, 332.0^{\circ}$ & 6.36 & 30 \\
Island lake (CAN) & isll & $64.25^{\circ}, 332.4^{\circ}$ & 5.30 & 30 \\
Ivalo (SGO) & iva & $65.28^{\circ}, 108.6^{\circ}$ & 5.72 & 30 \\
Jyväskylä (SGO) & jyv & $59.13^{\circ}, 103.6^{\circ}$ & 3.80 & 32.4 \\
Kilpisjärvi (IRIS) & kil & $66.10^{\circ}, 103.9^{\circ}$ & 6.09 & 38.2 \\
Oulu (SGO) & oul & $61.82^{\circ}, 105.1^{\circ}$ & 4.48 & 30 \\
Pinawa (CAN) & pina & $60.59^{\circ}, 330.8^{\circ}$ & 4.15 & 30 \\
Rabbit Lake (CAN) & rabb & $67.36^{\circ}, 317.9^{\circ}$ & 6.75 & 30 \\
Rovaniemi (SGO) & rov & $63.56^{\circ}, 106.4^{\circ}$ & 5.04 & 32.4 \\
Sodankylä (SGO) & sod & $64.18^{\circ}, 107.2^{\circ}$ & 5.27 & 30 \\
Taloyoak (CAN) & talo & $78.83^{\circ}, 329.3^{\circ}$ & Polar cap & 30 \\
\hline
\end{tabular}

Finnish riometers being $2.6-3 \mathrm{~h}$ of MLT ahead of UT and the Canadian riometers lagging UT by $6.5 \mathrm{~h}$.

Monitoring of less energetic precipitation has been provided by the Far Ultra Violet (FUV) camera on board the IMAGE spacecraft (Mende et al., 2000). The energy of the particles that produce emission in the far UV $(\sim 1-15 \mathrm{keV})$ overlaps the lower energy of those that produce some cos- mic radio absorption in the ionosphere. More importantly the FUV instrument provides global maps of the auroral precipitation such that the widely spaced point measurements of the riometers can be placed in context. The images that are shown in this paper have been processed to remove dayglow (e.g. Immel et al., 2000) and contributions from proton aurora. Subsequently electron mean energies and fluxes have 


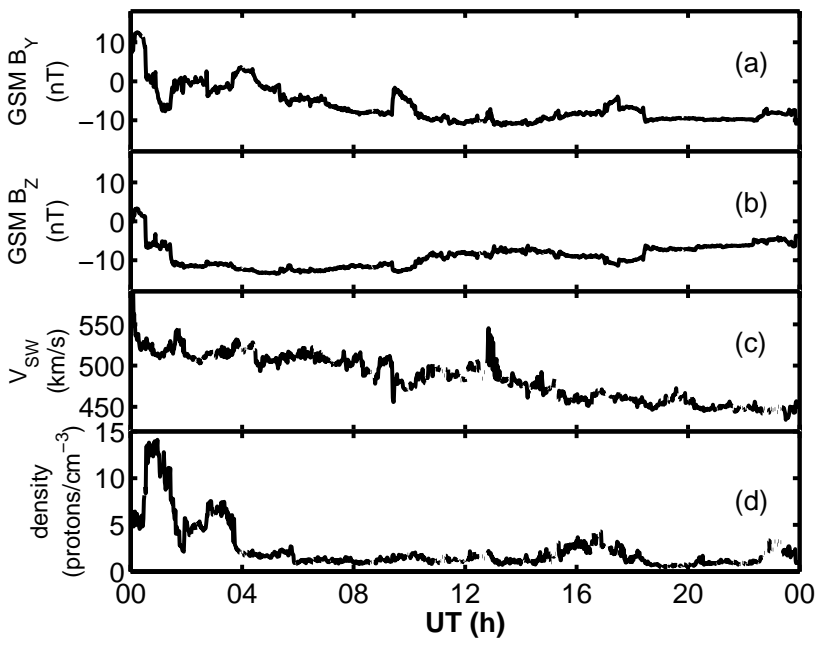

Fig. 2. Solar wind parameters from the ACE spacecraft: (a) IMF $B_{Y}$ in GSM; (b) IMF $B_{Z}$ in GSM; (c) solar wind speed; (d) solar wind proton density. These data have been propagated to the bowshock via a minimum variance analysis technique.

been determined from the emission measurements (e.g. Frey et al., 2003).

Satellite borne instruments also provide observations of the corresponding magnetospheric variations during the sawtooth event. The SOPA (Synchronous Orbit Particle Analyzer) instrument, on board the LANL (Los Alamos National Laboratory) geostationary satellites, measures electron fluxes from $50-26000 \mathrm{keV}$; in this paper only the seven lower energy channels $(50-315 \mathrm{keV})$ are used. The fluxes are spin averaged (1 min values) and provide clear indications of when electron injections occur at geostationary orbit. Magnetic field measurements have been provided by two of the Geosynchronous Operational Environmental Satellites (GOES-8 and GOES-10), which carry twin-fluxgate magnetometers (Singer et al., 1996). The measurements have been transformed into GSM (Geocentric Solar Magnetospheric) coordinates (Russell, 1971) and we have calculated the inclination of the magnetic field relative to the GSM equatorial plane. Table 2 lists the locations of the geostationary satellites used in this study, calculated using the IGRF-2000 model (Mandea et al., 2000), and Fig. 1b shows their locations in McIlwain (dipole) L-Shells and MLT along with the equatorial projections of some of the riometer sites.

\section{Observations}

\subsection{Overview}

Solar wind data have been taken from ACE (Advanced Composition Explorer) near the L1 point; the spacecraft was south of the ecliptic plane (between 7 and $19 R_{E}$ ) and 26-32 $R_{E}$ in the GSM Y direction. Figure 2 shows data from the mag-

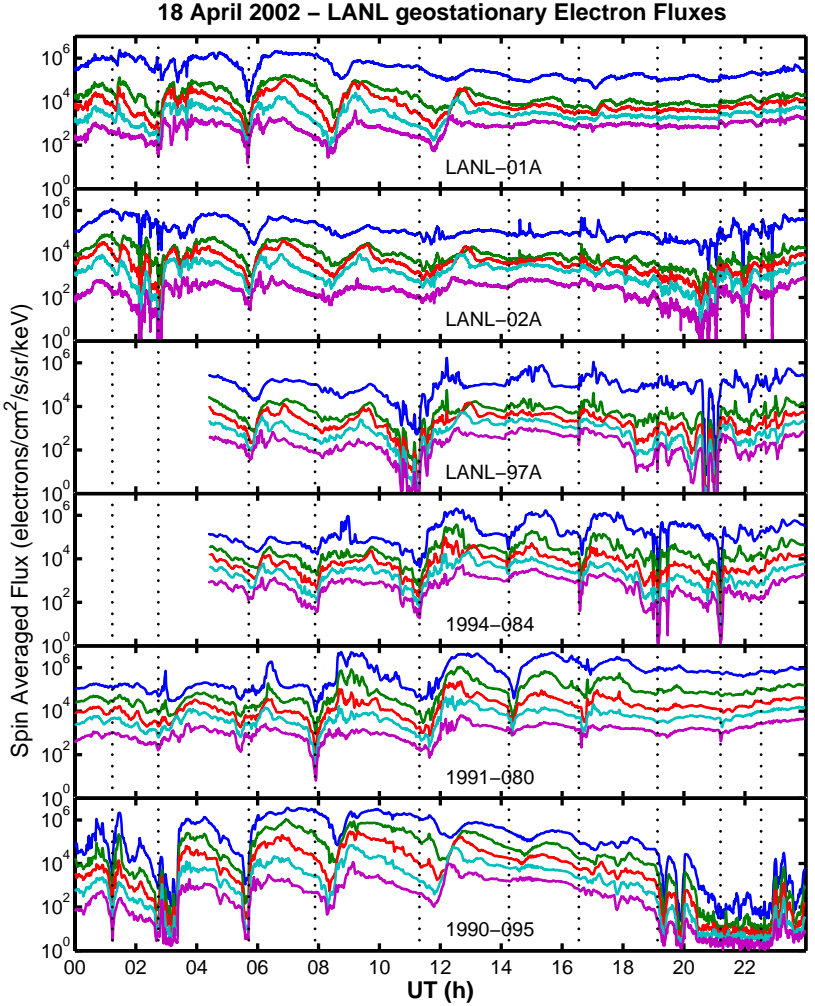

Fig. 3. Electron flux measured by the geostationary LANL satellites on 18 April 2002. The energy channels are 50-75 keV (blue), 75$105 \mathrm{keV}$ (green), 105-150 keV (red), 150-225 keV (cyan) and 225$315 \mathrm{keV}$ (magenta).

netic field (MAG) and solar wind (SWEPAM) instruments (Smith et al., 1998; McComas et al., 1998); the data have been time-shifted to the bowshock using a minimum variance analysis technique based upon the work of Weimer et al. (2003). The top two panels (a-b) display the IMF $B_{Y}$ and $B_{Z}$ components respectively; $B_{Y}$ was predominantly westward throughout the day except for an hour after midnight and $B_{Z}$ was mostly negative (southward), moving gradually northward as the day progressed. Panel (c) shows the solar wind velocity, which generally slows as the day progresses. Proton density (d) drops from 14.4 to $0.9 \mathrm{~cm}^{-3}$ by $05: 50 \mathrm{UT}$, fluctuating between 0.5 and $4 \mathrm{~cm}^{-3}$ thereafter, resulting in dynamic pressure values of less than $1.5 \mathrm{nPa}$ after 03:10 UT.

Figure 3 shows the electron fluxes from the six LANL satellites that were operating during the storm. No data were available for LANL-97A and 1994-84 before 04:25 UT; however, as many as nine injections were observed in the electron measurements when all satellites are considered. Decreases in the electron flux are followed by sharp increases resulting in the "sawtooth" profile. Dispersion in energy (e.g. 1990095 at 12:00 UT) indicates that the observing satellite is outside of the injection region and electrons gradient-curvature drift into the field of view. 
Table 2. Satellites used in this study. Columns from left to right display the following: satellite name/number; mean magnetic longitude with maximum/minimum indication; mean L-shell with extremes indicated; magnetic local time in terms of universal time. These parameters have been calculated using the International Geomagnetic Reference Field model.

\begin{tabular}{llll}
\hline Satellite & Magnetic longitude (degrees) & L shell (Earth Radii) & MLT (hours) \\
\hline $1990-095$ & $34.16^{\circ} \pm 0.25^{\circ}$ & $6.75 \pm 0.08$ & UT -2.09 \\
$1991-080$ & $266.79^{\circ} \pm 0.28^{\circ}$ & $6.64 \pm 0.003$ & $\mathrm{UT}-10.29$ \\
$1994-084$ & $216.39^{\circ} \pm 0.04^{\circ}$ & $6.74 \pm 0.05$ & $\mathrm{UT}+10.11$ \\
LANL-97A & $175.27^{\circ} \pm 0.29^{\circ}$ & $6.81 \pm 0.12$ & $\mathrm{UT}+6.83$ \\
LANL-01A & $80.07^{\circ} \pm 1.05^{\circ}$ & $6.62 \pm 0.05$ & $\mathrm{UT}+1.22$ \\
LANL-02A & $141.01^{\circ} \pm 0.79^{\circ}$ & $6.74 \pm 0.21$ & $\mathrm{UT}+4.13$ \\
GOES-8 & $356.48^{\circ} \pm 0.06$ & $6.85 \pm 0.01$ & $\mathrm{UT}-5.05$ \\
GOES-10 & $296.37^{\circ} \pm 0.01$ & $6.66 \pm 0.01$ & $\mathrm{UT}-9.63$ \\
\hline
\end{tabular}

Figure 4a shows the CNA from five of the CANOPUS riometers in the meridional Churchill Line; the low CNA at Taloyoak indicates that this riometer is in the polar cap for the entire day. The high geomagnetic activity on this day, caused by the prolonged southward (IMF), led to a maximum (peak $=9.6 \mathrm{~dB})$ in the absorption oval close to Pinawa, $\left(60.59^{\circ} \mathrm{N}\right)$ with a daily mean absorption of $1.5 \mathrm{~dB}$ compared with $0.6 \mathrm{~dB}$ (peak $=5.2 \mathrm{~dB}$ ) at Island Lake, the next highest. In Fig. $4 \mathrm{~b}$ the data from the Finnish riometers are displayed; in this sector absorption maximizes close to $63.6^{\circ} \mathrm{N}$ (Rovaniemi: mean $=1 \mathrm{~dB}$, peak $=8.6 \mathrm{~dB}$ ). Some absorption spikes, corresponding to later injections, can be seen later in the day as the riometers approach local midnight. The relative weakness of the response in comparison with the Canadian riometers is readily explained if one examines the LANL data presented in Fig. 3; note that the flux increases associated with each injection post 16:00 UT are much smaller than the earlier injections.

For this study only three of the "teeth" are considered (between 02:00 and 10:00 UT) to provide optimum configuration of the riometers. The CANOPUS instruments were in the night sector where they are most likely to respond to direct substorm precipitation, and the Lancaster/SGO riometers are in the morning sector (from dawn to noon) where dayside absorption tends to maximise (e.g. Kavanagh et al., 2004). In this section we present the observations related to each injection before discussing the implications of the day and night observations separately in Sect. 4 (Discussion).

\subsection{Injection A: 03:22 UT}

Figure 5 shows the selected injections during 18 April 2002. The top two panels display electron fluxes from the 1990-095 and 1991-080 spacecraft; the three vertical black lines (A, B and $\mathrm{C}$ ) demonstrate the times of non-dispersed injections observed by the two satellites. The third panel shows the angle, $\theta$, between the vertical and horizontal (GSM) magnetic field components measured by GOES- 8 (blue line) and GOES-10 (green line); in general lower angles indicate more stretched field configurations. In the bottom panel the absorption from the Gillam riometer is displayed; relative locations of the instruments can be seen in Fig. 1b.

The first marked injection is at 03:22 UT (from 1990-095) and occurred with a dipolarization at GOES-8 $\left(\Delta \theta=20^{\circ}\right)$; however, some forty minutes before the sharp rise in electron flux observed by 1990-095 there is a smaller, more variable flux enhancement (02:40 UT) consisting of four clear impulsive increases. This coincides with a rise in the flux at 1991-080 and a sharp $\left(\Delta \theta=45^{\circ}\right)$ dipolarization in the magnetic field at GOES-10, though only a small increase in $\theta$ occurs at GOES-8. The IMAGE FUV camera also records an increase in emission; a V-shaped enhancement of a preexisting arc structure at the dusk terminator (data not shown). The enhancement is orientated such that there are simultaneous brightenings at high and low auroral latitudes. On the ground Gillam (Fig. 5, bottom panel) shows a sharp enhancement in the CNA close to the time of this injection $(\sim 4 \mathrm{~min}$ later) followed by further enhancements. This riometer also records a large spike $(\sim 3 \mathrm{~dB})$ above a background of $\sim 1 \mathrm{~dB}$ absorption, shortly after the injection in the 1990-095 data at 03:22 UT. Around this time 1991-080 observes a dispersed flux signature, probably linked to the previous injection.

Figure 6 shows data from the Meridian Scanning Photometer (MSP) located at Pinawa. The $557.7 \mathrm{~nm}$ (a) and $630.0 \mathrm{~nm}$ (b) emissions generally correspond to precipitation from electrons with energy of a few $\mathrm{keV}$ and $<1 \mathrm{keV}$, respectively. Panels (c) to (e) compare CNA with the emission from the relevant latitudes for Gillam, Island Lake and Pinawa; several scan positions of the MSP have been averaged to account for the larger field of view of the riometer. The initial "tooth" (A) has been split into two and marked, with dashed lines A1 and A2, corresponding to the two injections. There is a quiet arc in the optical data which develops into an expansion onset at 02:38 UT expanding both poleward and equatorward from Pinawa and the CNA spike moves equatorward. The absorption and optical signatures have similar morphology, suggesting that the electrons producing the 

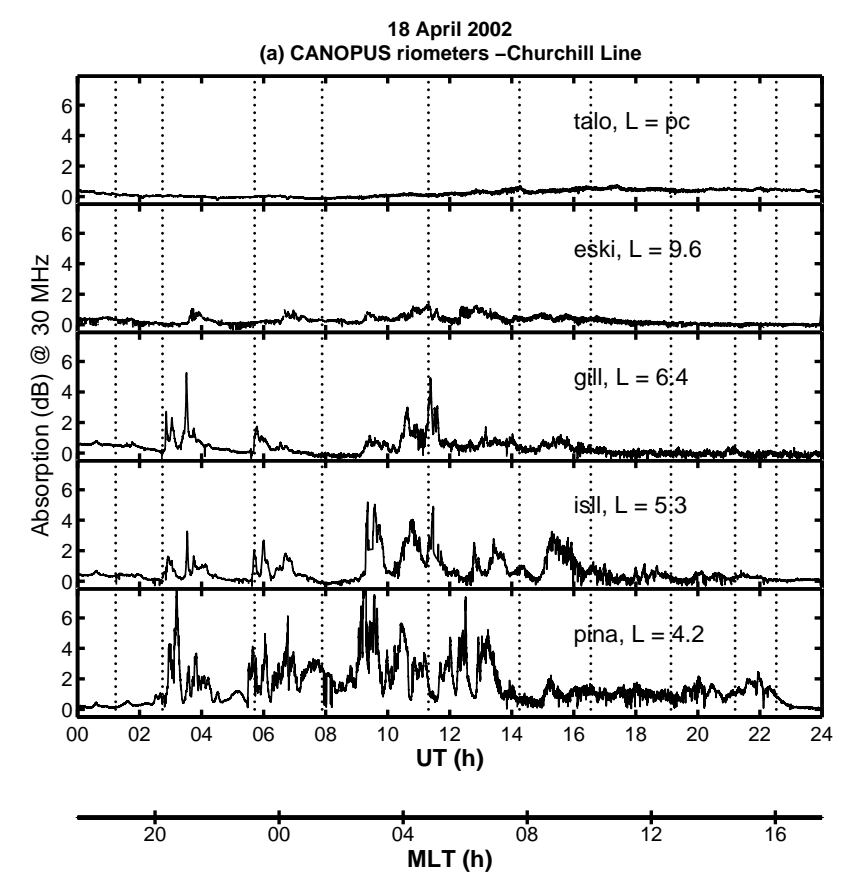

(b) IRIS and SGO riometers

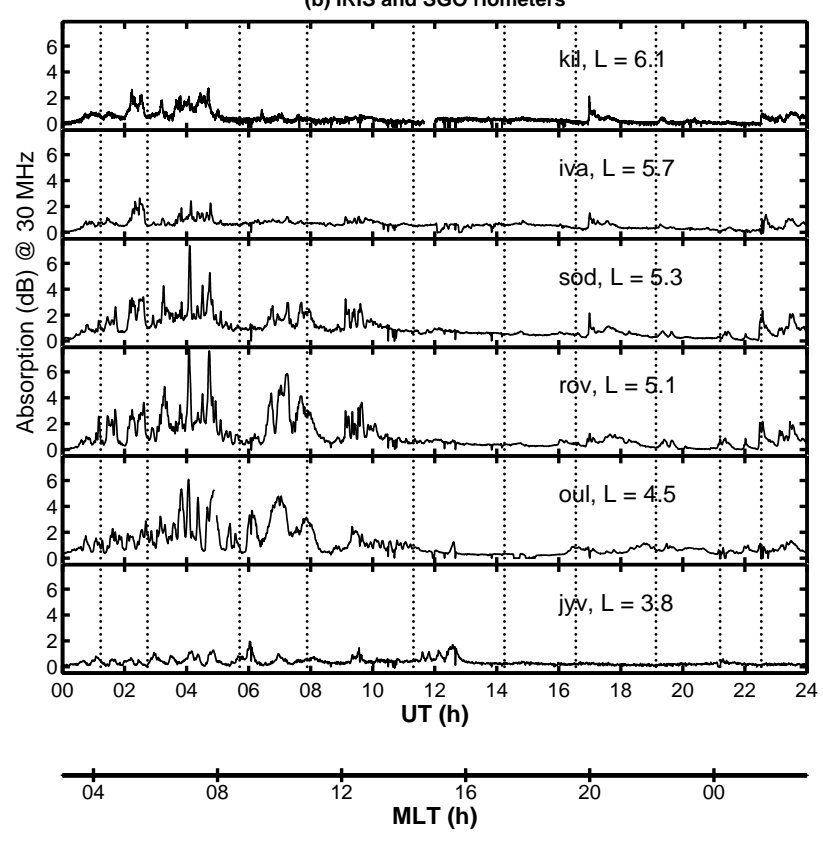

Fig. 4. (a) Cosmic noise absorption (CNA) from five of the Churchill line riometers. Corresponding L-shells are labelled; pc refers to "polar cap" where Taloyoak (talo) is on open field lines. The second $\mathrm{x}$-axis demonstrates the average magnetic local time for the five riometers. (b) CNA from IRIS (kil) and the SGO riometers in the Finnish sector. All values of decibels $(\mathrm{dB})$ are given for $30 \mathrm{MHz}$.

emission $(\sim 1 \mathrm{keV})$ and those creating CNA $(>30 \mathrm{keV})$ are being precipitated via the same mechanism.

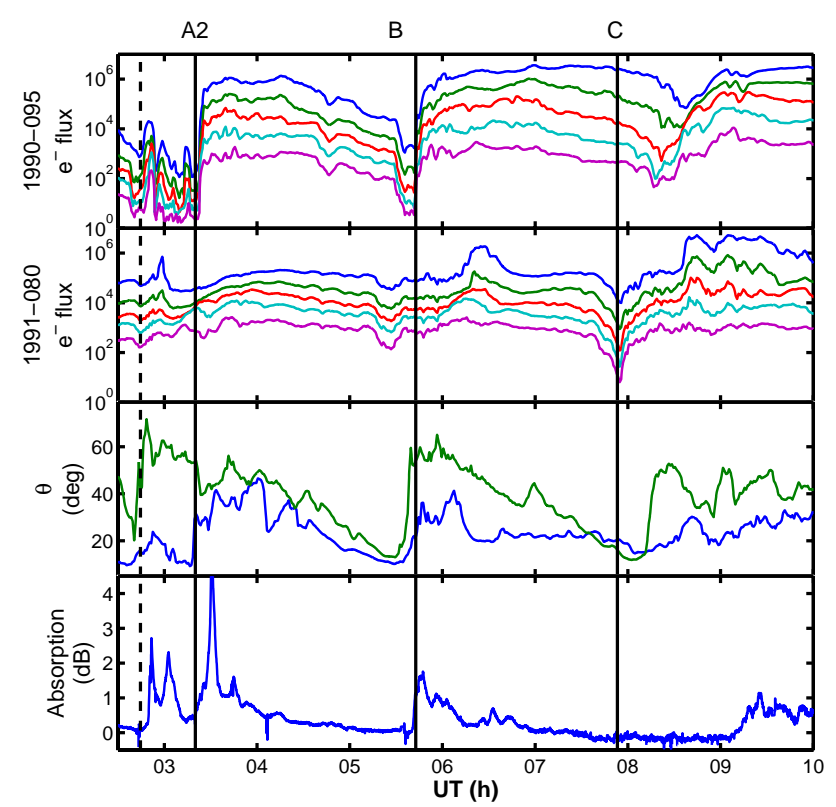

Fig. 5. LANL, GOES and Gillam riometer data on the 18 April 2002 from 02:30 UT to 10:00 UT. The top two panels show the electron fluxes from two of the LANL satellites near to the CANOPUS riometers; the energy channels are described in Fig. 3 caption. The third panel shows the elevation angle, $\theta$, of the geomagnetic field recorded by the GOES 8 (blue line) and GOES 10 (green line). The bottom panel shows the auroral absorption measured by the Gillam riometer. The vertical black lines (marked A, B and C) demonstrate the approximate times of particle injections. The dashed, vertical black line notes the position of an additional dipolarization.

The evidence suggests that there are actually two injections occurring within $\sim 40 \mathrm{~min}$. Figure 7 shows the $\mathrm{H}$ component (northward) of the magnetometer stations in the Churchill line (no data were available from Taloyoak) after subtraction of the daily mean. A negative bay is observed by the three most equatorward magnetometers with a largest change at Pinawa; the downward excursion begins at 02:38 UT (coincident with the onset of the optical brightening shown in Fig. 6) and reaches $-255 \mathrm{nT}$ (from $400 \mathrm{nT}$ ) at $02: 57 \mathrm{UT}$ before decreasing further to $-410 \mathrm{nT}$ by 03:12 UT. Following this is a second negative bay observed by all of the magnetometers and peaks at Gillam by 03:30 UT (from $400 \mathrm{nT}$ to $-700 \mathrm{nT}$ ). Figure 8 shows CNA recorded by the Fort Smith and Fort McMurray riometers, west of the Churchill line. Fort McMurray observes a sharp absorption increase at 02:44 UT which subsequently expands poleward to Fort Smith 3 min later. Figure 9 shows the data from the azimuthal chain of riometers. There is a small spike at Dawson and a stronger response at Fort Simpson; these data seem to indicate a rapid eastward motion of the absorption at the same time as the poleward motion shown in Fig. 8.

Figure 10 presents the electron flux measured by LANL01A and LANL-02A with the absorption from IRIS and the 


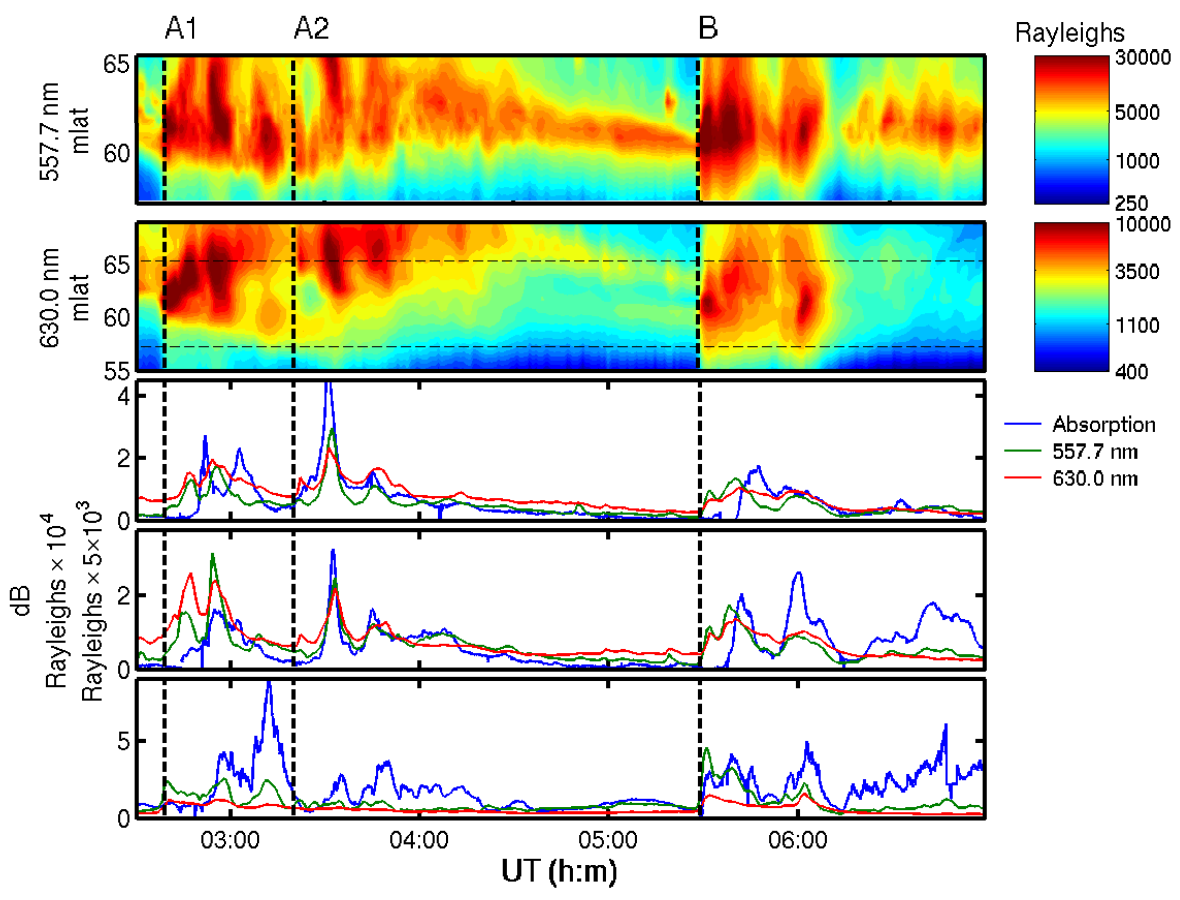

Fig. 6. These data come from the meridian scanning photometer (MSP), located at Pinawa, on 18 April 2002. The top two panels show the two emissions: $557.7 \mathrm{~nm}$ (a) and $630.0 \mathrm{~nm}$ (b). The horizontal black lines in (b) denote the field of view of the 557.7 filter (lower altitude emission. The bottom three panels show data from Gillam (c), Island Lake (d) and Pinawa (e); adjacent latitude scans have been averaged to account for the larger beam sizes of the riometers. The three vertical, dashed lines represent the approximate times of the electron injections (A1, A2 and B). Reliable data were not available for substorm C.

SGO chain from 02:30 UT to 10:00 UT. There is a dispersed energy signature at LANL-01A (04:00 MLT) following A1 beginning at 02:45 UT, thus the riometers are outside of the injection region. The absorption at Kilpisjärvi occurs between the peak fluxes at LANL-01A and LANL-02A rather than linked to the leading edge of the flux enhancement. There is an L-shell dispersion at the onset time of the absorption, and the CNA at Rovaniemi and Sodankylä is twice the magnitude of that at Kilpisjärvi $(\mathrm{L}=6.1)$.

A2 has a smaller response in the satellites but the riometers observe an increase in absorption some $11 \mathrm{~min}$ after the injection is recorded at 1990-095. This time the absorption is notable at Kilpisjärvi ( $\sim 2 \mathrm{~dB})$ but is still significantly higher at Rovaniemi on occasions (e.g. at 04:05 UT). This absorption decays to background levels by $\sim 05: 10$ UT. Jyväskylä sees small increases $(<1 \mathrm{~dB})$ however the absorption is consistently low. It is worth noting at this point that the riometers are sensitive to particles that enter the loss cone and consequently precipitate into the ionosphere whereas SOPA measures electron fluxes at all pitch angles. Consequently, although similar structure may appear in the LANL and riometer data, one would only expect a direct correspondence if there is strong pitch angle scattering of the electrons (e.g. Baker et al., 1981). At other times only a fraction of the electron flux (depending on the effectiveness of the scattering mechanism) measured by LANL is observed by the riometers.

\subsection{Injection B: 05:40 UT}

Injection B, observed by 1990-095 at 05:40 UT (Fig. 5), consists of a single flux enhancement of similar magnitude to the injection at 03:22 UT. Both GOES 8 (05:34 UT) and GOES 10 (05:32 UT) record a dipolarization of the magnetic field. The riometer at Gillam witnesses a $2 \mathrm{~dB}$ rise at approximately the same time; this increase is smaller than the previous event and there is no easily discernable spike event. In this case the absorption displays a poleward motion (Fig. 6) that reflects the expected CNA response to the onset of a substorm (Hargreaves, 1974) and is consistent with the optical data. The changing ratio of the $557.7 \mathrm{~nm}$ emission to the CNA suggests that there is either a hardening of the precipitation spectrum as time progresses (Fig. 6) or a change in the effectiveness of pitch angle scattering. The similarity of the structure suggests that the precipitating electrons are from the same source population. The magnetometer data (Fig. 7) also shows a poleward motion of the negative bay in the $\mathrm{H}$ component, starting at $\sim 05: 30 \mathrm{UT}$.

Figure 11 consist of snapshots of the Ultra Violet (UV) emission (from IMAGE), taken at 2 min resolution and mapped onto a geographical and local time grid. The auroral 


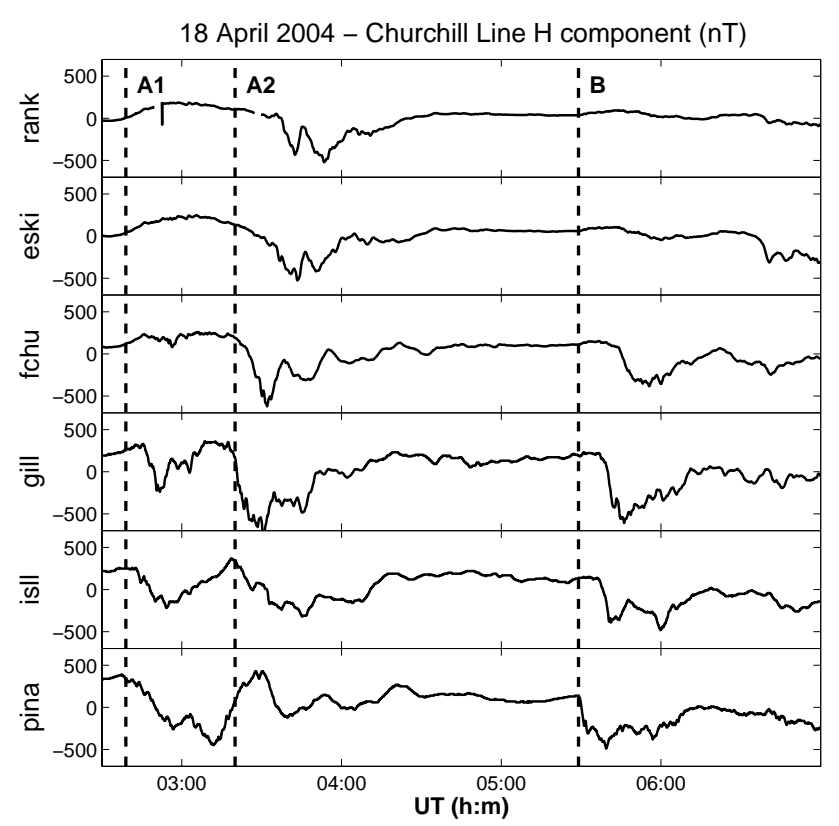

Fig. 7. Magnetograms from six magnetometers in the Churchill line displaying the $\mathrm{H}$ component for 02:30 UT to 07:00 UT on 18 April 2004. Daily averages of the measurements have been subtracted from the data to highlight variations in the magnetic observations.

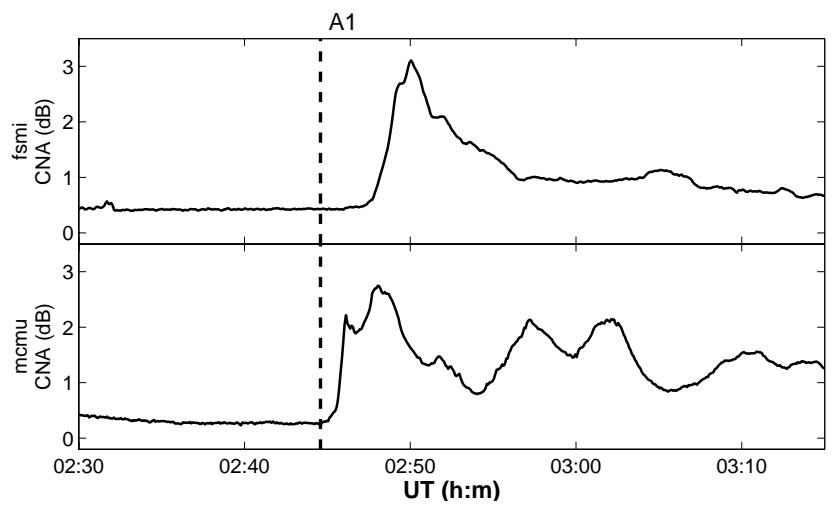

Fig. 8. Cosmic Noise Absorption from the two riometers at Fort Smith and Fort McMurray, which comprise part of the second CANOPUS meridional chain. Once again the dashed vertical lines represent the estimated times of electron injections.

oval is quiet at 05:22 UT and the emission shows a small increase near 03:00 LT. At 05:30 UT there is an intense brightening at $\sim 23: 00$ LT which expands such that by 05:45 UT there is a clear auroral bulge at the northwest edge of the brightest emission.

LANL-01A is located at 06:50 MLT for injection B and records a distinct, non-dispersed injection at 05:40 UT (Fig. 10). LANL-02A sees a dispersed signature, beginning at 05:44 UT, placing the edge of the injection region between 06:50 and 09:50 MLT. There is an increase in

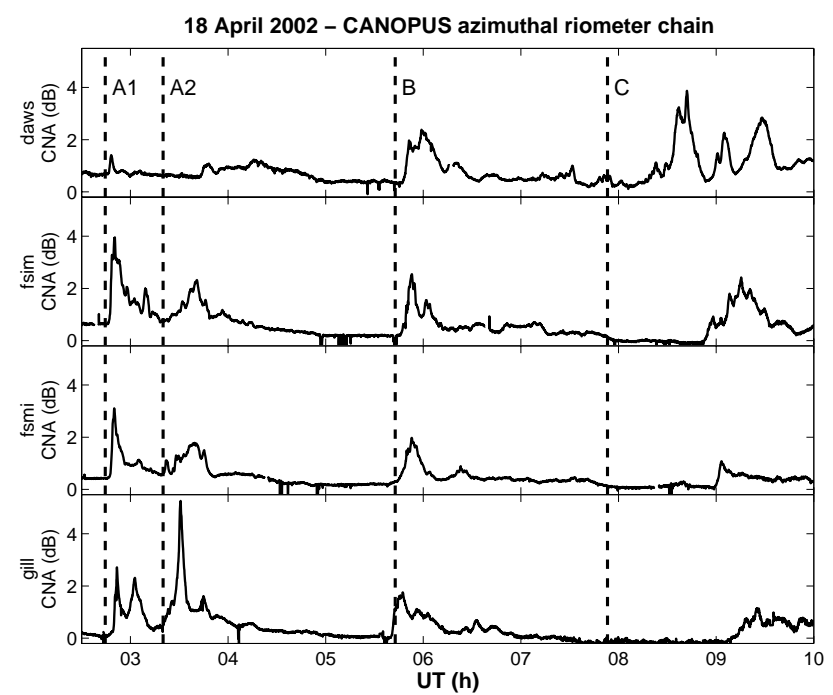

Fig. 9. Cosmic Noise Absorption from the azimuthal chain of CANOPUS riometers (including Gillam). These riometers between magnetic latitudes of $66.1^{\circ}$ to $67.2^{\circ}$. Vertical, dashed lines indicate estimated times of substorm onsets.

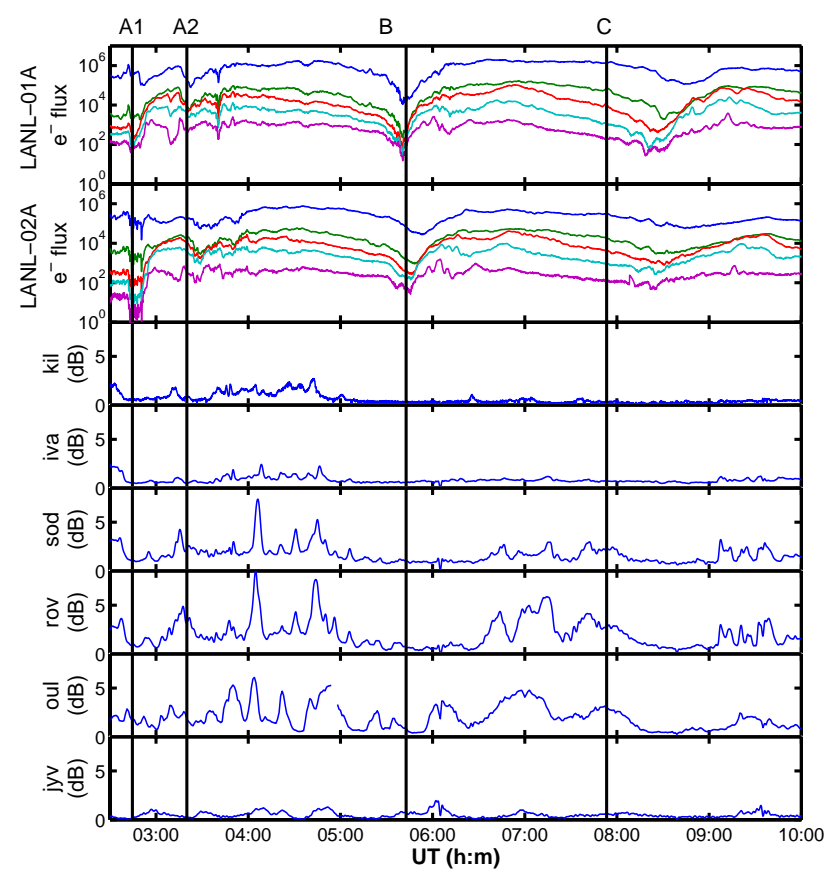

Fig. 10. Dayside observations of geostationary electron flux and riometer absorption in Finland. The vertical, solid lines show the timing of the onsets of the 4 injections. The top two panels show the electron flux (energy channels described in Fig. 3 caption) from satellites either side of the line of riometers. The bottom six panels show the morning absorption from IRIS (kil) and the SGO riometers. 


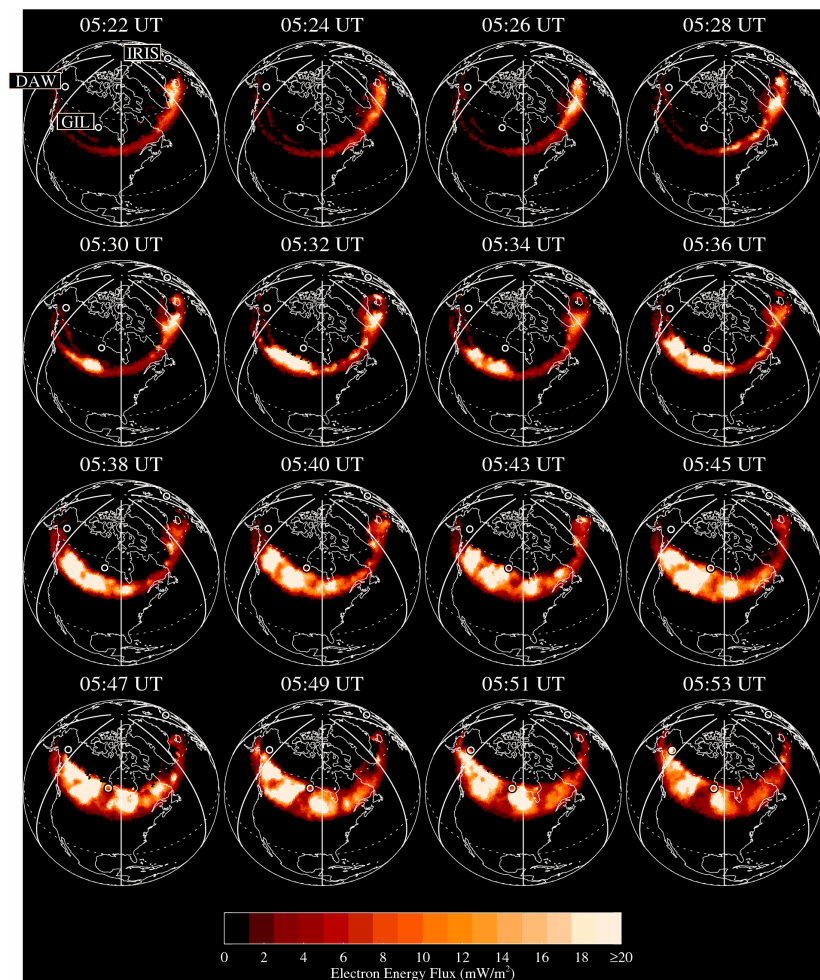

Fig. 11. Maps of Northern Hemisphere FUV emission converted to electron energy flux $\left(\mathrm{mW} / \mathrm{m}^{2}\right)$ recorded by the camera on board the IMAGE satellite on 18 April 2002. These cover the onset of substorm B from 05:22 UT to 05:53 UT.

absorption at Jyväskylä starting at 05:30 UT and peaking just after 06:00 UT $(\sim 1.9 \mathrm{~dB})$, but this riometer is situated at a point distant from the geosynchronous footprint. The timing makes it extremely unlikely that this increase is directly associated with the injection and none of the other riometers observe an increase immediately following the injection. The LANL satellites (01A and 02A) observe further flux increases (beginning at 06:10 UT and 06:15 UT, respectively) which are dispersed in energy, the timing of which suggests that they are drift echoes of the initial injection (e.g. Reeves et al., 1990). The flux in the highest plotted energy channel of LANL-01A (225-315 keV) peaks first at 06:01 UT and the peak in the dispersed signature returns $27 \mathrm{~min}$ later. This is consistent with an estimate of the drift period of an equatorially mirroring electron with energy of $256 \mathrm{keV}$ in a dipole field. The riometers at Sodankylä and Rovaniemi record increases in absorption starting at $\sim 06: 30 \mathrm{UT}$, which is shortly after the rise in flux at LANL-01A. Kilpisjärvi does see a solitary increase, at 06:25 UT, associated with the rise in flux but nothing after that.

\subsection{Injection C: $\sim 07: 55 \mathrm{UT}$}

A weak injection at 07:55 UT is clear in the 1991-080 measurements at $\sim 21: 40$ MLT (Fig. 5) followed by a dis-

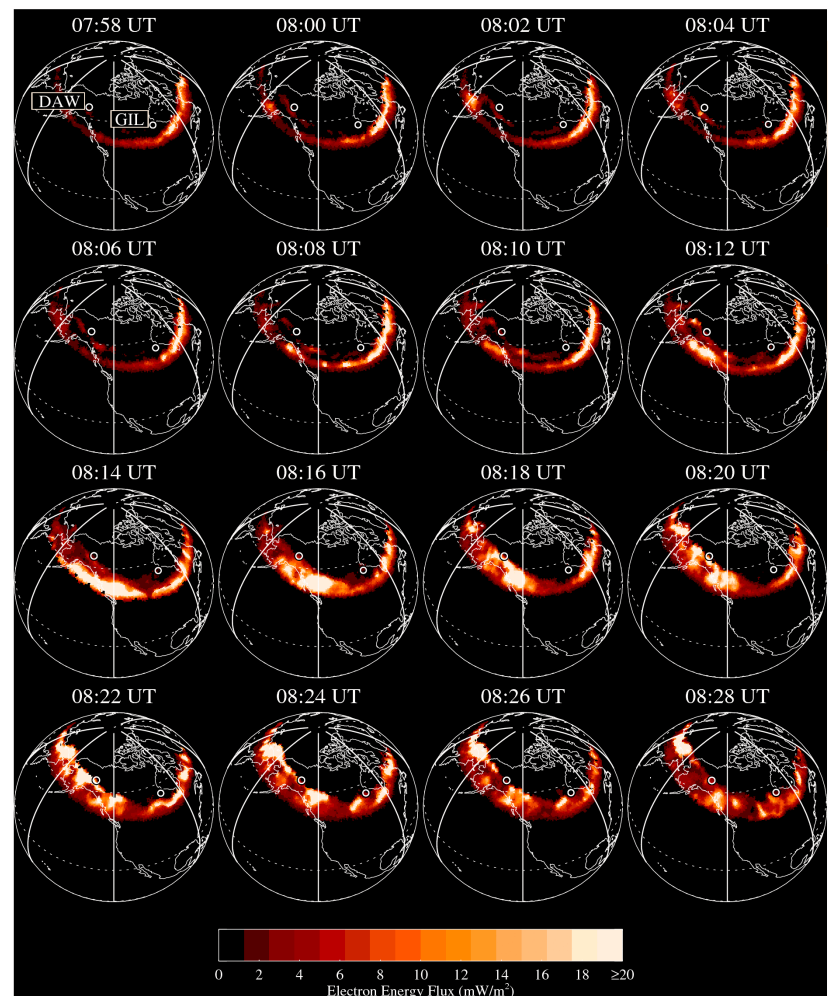

Fig. 12. Maps of Northern Hemisphere FUV derived electron energy flux $\left(\mathrm{mW} / \mathrm{m}^{2}\right)$ on 18 April 2002. These images run from 07:49 UT to 08:35 UT (four minute snapshots) and cover the apparent injection at 07:55 UT and the onset at 08:12 UT during event C.

tinct dipolarization signature recorded by GOES-10 some $30^{\circ}$ longitude towards midnight and $15 \mathrm{~min}$ later. The 1994-084 satellite also observes an increase at $\sim 07: 55$ UT ( 18:00 MLT) (see Fig. 3). Close to dawn the 1990095 satellite shows dispersion as do the LANL-01A $(\sim 09: 15$ MLT) and LANL-02A ( 12:00 MLT) satellites.

There is no absorption increase at Gillam associated with either the injection at 07:55 UT or the dipolarization at 08:12 UT and the electron flux is two orders of magnitude less than in the preceding injections. There is an absorption enhancement at Gillam shortly after 09:05 UT, approximately an hour after the injection onset. This follows an increase in the flux at geostationary orbit (e.g. 1991-080). Riometers west of Gillam observe an increase in absorption at progressively earlier times (Fig. 9), though there is a thirtyfive minute separation between the onset at Dawson and the response at Fort Simpson. LANL-02A and LANL-01A see dispersed signatures as the electrons gradient curvature drift into the dayside (Fig. 10) and at 09:06 UT the Finnish riometers were close to noon and they observed an increase in absorption at the lower latitudes.

Figure 12 shows the UV emission at this time; a distinct, quiet auroral arc can be seen at 07:49 UT and no significant activity occurs until 08:12 UT when a distinct enhancement 
appears in the pre-midnight sector. This expands predominantly westward with increased brightenings close to dusk by 08:22 UT. The enhancements remain confined between $\sim$ 17:00 LT and $\sim 01: 00 \mathrm{LT}$ and no significant increases in emission are measured above the Churchill Line riometers. The increase in CNA that peaks at 08:30 UT at Dawson coincides with a rise in the total flux recorded by 1991-080 to $5 \times 10^{6}$, which is a factor of 30 greater than at 08:15 UT.

\section{Discussion}

\subsection{Overview}

On 18 April 2002 the magnetosphere displayed quasiperiodic injections of energetic particles from the magnetotail to the inner magnetosphere (Fig. 3) during a geomagnetic storm. In general the storm led to increased ionisation in the D-layer that resulted in enhanced CNA. Figure 4 demonstrates that the absorption is high in both the Canadian and Finnish sectors and that the absorption oval has expanded in response to the solar-wind/IMF driving of the magnetosphere. The absorption maximises at lower magnetic latitudes in Canada than in Finland by approximately 3-4 degrees, in agreement with previous statistical studies of absorption (e.g. Hargreaves, 1966, and references therein). A loss of absorption occurs at higher latitudes in Finland as the event progresses, somewhat at odds with the findings presented by Hargreaves (1968) who determined that increases in activity are likely to shift the maximum absorption (which increases) to lower latitudes, but not to reduce the absorption at higher latitudes. This is likely true in general when the increased absorption is driven by high solar wind speeds and pressure changes, but in this case the motion to lower latitudes is predominantly caused by an enlarged polar cap, associated with a long period of southern IMF $B_{Z}$.

The absorption follows the diurnal pattern highlighted in statistical studies (e.g. Kavanagh et al., 2004, and references therein) such that there is a maximum occurrence of CNA in the morning sector and around midnight but a notable minimum in the afternoon. There is a sustained enhancement at Pinawa between 15:00 and 23:00 UT (mean $=1.13 \mathrm{~dB}$ ) which is possibly the result of a steady drizzle of radiation belt electrons at $\mathrm{L}=4$, but this is not investigated here.

As well as the three main injections (A1, B and C) another has been identified (A2); this occurs some 40 min after A1. The timing of the observations makes it highly unlikely that this is caused by an expansion of the original dipolar region; this would result in a rapid acceleration of the expansion from $0.05^{\circ} \mathrm{s}^{-1}$ (delay between the GOES spacecraft) to $0.3^{\circ} \mathrm{s}^{-1}$. It is possible that either A1 or A2 is actually a pseudobreakup (e.g. Koskinen et al., 1993) although much of the data suggest that they are substorms. It appears that following the auroral activation accompanying injection $\mathrm{A} 1$ growth continues away from the region of dipolarization (due to con- tinued energy input from the solar wind) leading to a second injection and auroral enhancement (at A2). The break-up accompanying A2 starts at higher latitudes; the photometer (Fig. 6) and magnetometer (Fig. 7) data shows the auroral signature to begin at Gillam rather than Pinawa. Following injection A1, open magnetic flux is closed, shrinking the polar cap, and the dayside reconnection rate is insufficient to return the flux to the pre-substorm level before the next expansion onset. Huang et al. (2003b) identified injection A1 as a substorm through observations by GEOTAIL (Kokubun et al., 1994) of a travelling compression region related to plasmoid formation in the magnetotail as well as observations of proton flux enhancements by 1991-080 (16:00 MLT).

These observations suggest that additional and/or more complicated activity may occur within the quasi-periodic $2-$ $4 \mathrm{~h}$ sawtooth timeframe. The cause for this particular deviation may be found in the solar wind conditions at the time (Fig. 2); $B_{Y}$ was eastward (positive) at 02:48 UT (accounting for the delay to Earth) and then turned sharply westward (negative) before the second injection (A2); the first injection (A1) also corresponded with a rise in the dynamic pressure $(1 \mathrm{nPa})$ above an already increased level. Conditions for subsequent injections were much more stable thus this "double event" may have been triggered by the more variable solar wind. Changes in the magnetospheric configuration might explain the reduced flux at some of the LANL satellites as the region of densest particle population moved across the satellites.

\subsection{Nightside absorption (Canadian sector)}

More insight into the dynamics of the particle precipitation may be gleaned from separate analyses of the night and dayside absorption signatures of the selected teeth. For the first 3 injections there are distinct examples of riometer absorption related to substorm activity. There is a poleward moving, weak onset at the Churchill line and a strong, poleward moving enhancement further west (Fig. 8) following injection A1. This is followed by equatorward moving enhancements ( $\sim 10 \mathrm{~min}$ after the first) in agreement with the current paradigm of auroral absorption during substorms (e.g. Ranta et al., 1981) that is described in Sect. 1. After 02:45 UT the CNA propagates eastward from a small spike at Dawson (Fig. 9) consistent with past observations of the substorm onset in absorption. Thus A1 has some of the general features of a "standard" absorption substorm but whether a growth phase absorption bay exists is difficult to assess due to the short timescales between intense activity-onsets. An interesting aspect to this injection is the structure of the geosynchronous flux enhancements; the injections are short lived ( $\sim 8 \mathrm{~min}$ in duration) and this may be the controlling factor behind the short duration of the CNA enhancements. In this case they would not be spike events in the classical sense (e.g. Hargreaves et al., 1997); rather they are the direct precipitation of short-lived injection bursts from the tail. 
The second injection (A2), at $\sim 03: 20 \mathrm{UT}$, has a welldefined equatorward moving CNA spike (Fig. 6), which decreases in magnitude as it moves south. The time difference between the dipolarization at GOES- 8 and the spike at Gillam is $11 \mathrm{~min}$ (separated by $24.48^{\circ}$ longitude), whereas during A1 it is $\sim 5$ min from GOES-10 to the first poleward moving spike $\left(11.62^{\circ}\right.$ separation). Thus there is time for a poleward propagating spike event to form outside of the field of coverage, possibly poleward and/or eastward of the riometers. Thus this absorption fits the substorm paradigm as well, including absorption that correlates well with the diffuse optical signature (e.g. Ansari, 1964). Westward motion of absorption before midnight, as seen in A2 (Fig. 9), is a feature of the global pattern of absorption motion defined by Hargreaves (1968). This type of motion shall be investigated with respect to injection $\mathrm{B}$ with the additional available diagnostics but is more a function of the location of the riometers within the injection region than a local time phenomenon.

For the third injection, $\mathrm{B}$, at $\sim 05: 30$ UT there is a poleward progression of a sharp onset (though not a clearly defined spike) that begins at Pinawa and is generally well correlated with the optical signature (Fig. 6). The decline in the ratio of the $557.7 \mathrm{~nm}$ emission to absorption indicates either that the spectrum of precipitation hardens or else the effectiveness of the pitch angle scattering increases. After $\sim 06: 20$ UT the slowly varying absorption structure (at Island Lake) suggests that it is related to drifting electrons of higher energy than those responsible for the discrete spikes (second category of absorption from Ansari, 1964).

The westward expansion of absorption (Fig. 9) from 05:40:50 UT to $05: 47: 25$ UT moves with a velocity of $\sim 0.15^{\circ} \mathrm{s}^{-1}$. It is unlikely that gradient-curvature drifting ions precipitate with enough intensity to produce the $1-2 \mathrm{~dB}$ absorption since the apparent motion suggests that the leading edge of drifting ions would have energy of $\sim 150 \mathrm{keV}$, leading to E-region deposition. Figure 13 shows time series from three pixels of the FUV camera corresponding to the locations of the Dawson, Fort Smith and Gillam riometers. The rise time of the emission (converted to electron energy flux) closely matches the absorption at the three locations suggesting that either the low energy electrons are moving with the same drift speed in the magnetosphere as the higher energies or else the precipitation is caused by some form of trigger moving independently of the particle drift speed. The apparent speed of the absorption (corresponding to $\sim 6.6 \mathrm{~km} \mathrm{~s}^{-1}$ in the $\mathrm{F}$ region ionosphere) is much higher than the typical convection speeds of a few hundred metres per second and the convection pattern derived from AMIE (Assimilative Mapping of Ionospheric Electrodynamics) (Richmond and Kamide, 1988) shows that the westward motion of absorption is within a region of eastward convection (pattern not shown) Hargreaves (1968) suggests that a fast mode magneto-sonic wave, propagating azimuthally from the midnight sector could trigger precipitation of an extant population of electrons. For this to occur the elec-

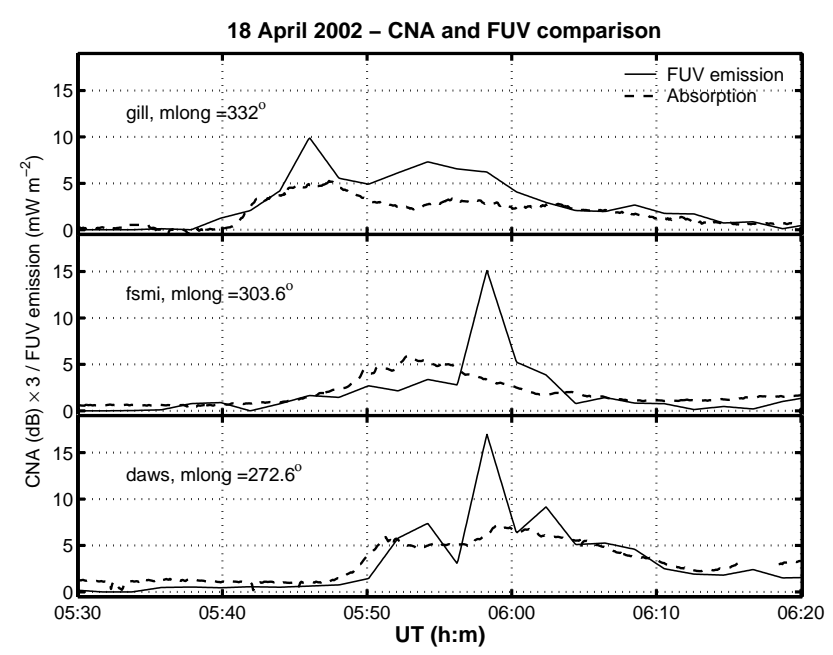

Fig. 13. Comparison of cosmic noise absorption with the electron energy flux derived from the FUV emission from closest pixel of the camera following Injection B on 18 April 2002. The stations, Gillam to Dawson, run east to west, respectively, and show the apparent westward motion of both the FUV emission and the CNA. The magnetic longitudes are marked on the plots.

tron flux must be above the critical stable trapping limit (e.g. Coroniti and Kennel, 1970) but here, the time between injection and precipitation is too short for the electron population to have increased following gradient curvature drift. A more likely explanation is that the apparent westward motion represents an expansion of the injection region where electrons are injected at progressively earlier local times (e.g. Thomsen et al., 2001).

Observations during the final injection, $\mathrm{C}$, provide conflicting information of when the onset of the potential substorm occurs. The 1991-081 and 1994-084 satellites record sharp injection fronts close to 07:57 UT (at 18:00 MLT and $\sim 21: 45$ MLT, respectively). The proton fluxes from the satellites also suggest a pre-08:00 UT injection (data not shown). However the GOES-10 magnetometer measures a dipolarization at 08:10 UT and the dispersed electron fluxes from the $02 \mathrm{~A}, 01 \mathrm{~A}$ and 095 spacecraft also suggest an injection closer to 08:10 UT. This later estimate ties in with the observations from the GEOTAIL satellite, as described by Lui et al. (2004), which observes a travelling compression region (TCR) related to a plasmoid at 08:15 UT when the spacecraft is $\sim 26 R_{E}$ down tail; however, since GEOTAIL is in the tail lobe at this time $\left(Z_{\mathrm{GSM}}=7.6 R_{E}\right)$ there will be a propagation delay between the passage of the plasmoid and the observation of the TCR. Thus connecting the timing of the TCR with the injection at geosynchronous orbit is difficult. The FUV camera (Fig. 12) records no enhanced emission at the time of the initial injection but does observe a strong onset at 08:12 UT; this softer precipitation is predominantly confined to the dusk-midnight sector. During an injection the auroral 
precipitation lies within the injection region but it cannot be reliably used as an identifier for the boundary of the injection region. In this case it suggests that the dipolarization region is heavily skewed towards dusk and this is reinforced by the observations from GOES 8 (at 03:00 MLT), which show no dipolarization at all. The explanation for this discrepancy in timing is not clear, although close inspection of the electron flux data from 1991-080 and 1994-084 suggest that the initial rise is followed by a slightly larger increase at $\sim 08: 12$ UT. The same is true of the proton flux: a small increase at $\sim 07: 56 \mathrm{UT}$, which peaks at 08:05 UT, followed by a decline and a second enhancement at 08:10 UT. Therefore it appears that there are two separate impulsive injections; the first is not accompanied by a dipolarization and results in low fluxes; the second is a sustained injection after the first rise and consists of higher fluxes of electrons. Thus the second injection accompanied an apparent substorm onset as identified from other signatures, although the dipolarization/injection region was confined in longitude to the dusk-midnight sector.

Most of the riometers were outside of the asymmetric injection region and consequently observed no absorption response. The rise in absorption after 08:10 UT suggests that Dawson is within the injection region. The following eastward expansion of the CNA spreads to Fort Simpson at 08:52 UT, Fort Smith by 08:59 UT and arrives at Gillam by 09:06 UT; this represents an apparent acceleration of the average absorption motion from $0.01^{\circ} \mathrm{s}^{-1}$ through $0.03^{\circ} \mathrm{s}^{-1}$ to $0.06^{\circ} \mathrm{s}^{-1}$. Although the instruments are most likely on different drift paths the radial separation cannot explain the timing of the CNA onset; one would expect a swifter response at Fort Smith and a longer delay at Gillam. A duskward electric field would lead to energisation of the drifting electrons in this time sector leading to an overall increase in the energy of electrons most responsible for absorption,. Conserving the first adiabatic invariant the energy increase is in the longitudinal direction leading to lower pitch angles and increased precipitation (Pellinen and Heikkila, 1984). This would lead to an increase in the gradient-curvature drift speed but should also result in an increase in absorption; the observed reduction could be a consequence of the radial distribution in the flux of electrons where the flux is highest at the L-shell connected to Dawson. Alternatively the reduction could be attributed to either an overall loss of flux at progressively later local times or a change from strong to weak pitch angle diffusion. It is currently impossible to determine the exact cause with the available data. However, the absorption structure at Fort Simpson is similar to that at Dawson but changes considerably at the other riometers, indicative of the precipitation spectrum is changing.

The CNA peak at Dawson occurs with a sharp, dispersionless, rise in the electron flux observed by 1991-080 (see Fig. 5); the total electron flux (50-315 keV) rose by over an order of magnitude from 08:15 UT $(\sim \times 30)$ to $08: 45$ UT. The non-dispersed nature of the signature suggests that this is an additional injection of particles rather than a drift echo of the previous injection. Although the sharp rise is not apparent in the other spacecraft a small dispersed signature appears some $45 \mathrm{~min}$ later at 1990-095 $(\sim \times 30$ flux increase from $10^{5}$ to $3.5 \times 10^{6}$ at $\left.\sim 09: 12 \mathrm{UT}\right)$. This increase seems to trigger the precipitation of drifting electrons that had been stably trapped even after the injection closer to 08:00 UT.

Kennel and Petschek (1966) suggested that in order for precipitation to begin whistler mode wave turbulence must occur. This only happens when the flux of electrons on a field line surpasses a critical level. Thus, it would appear that the electron flux injected between $\mathrm{L}=4$ and $\mathrm{L}=9$ is initially too low to produce precipitation. Ongoing injections raise the level of electron flux and lead to eventual precipitation. The meridional chains of riometers demonstrate a lack of Lshell dispersion in agreement with the non-dispersed electron flux signature. This places the eastward edge of this injection region between Fort Smith and 1990-095.

\subsection{Dayside absorption (Finnish sector)}

In the morning sector the first two injections (A1 and A2) produce fairly typical results: Dispersed signatures are observed at geostationary orbit by LANL-01A and LANL-02A and the CNA displays L-shell dispersion at onset. This is consistent with the effects of gradient-curvature drift, which predicts that particles on a higher L-shell should reach a particular longitude earlier than particles of the same energy at lower L-shells (e.g. Kavanagh et al., 2002, and references therein). The spike-like enhancements in CNA in the dayside ionosphere are not the same phenomenon as night-side spikes related to the substorm onset/injection. As the precipitation event progresses the L-shell dispersion disappears and much of the structure appears to be either coincident across L-shells or sometimes leading in the equatorward riometers. This may be attributed to the changing dominant energy combined with continuous injections over large regions of MLT. Another possibility is that some local effect in the magnetosphere is modulating the precipitation, such as interaction with a ULF wave (e.g. Coroniti and Kennel, 1970); this will be the subject of a future paper. It can be inferred from the higher absorption at lower latitudes at this time that either higher electron fluxes were present at lower $\mathrm{L}$ shells or else greater pitch angle scattering into the loss cone occurred. It is important to note that the flux measurements were made at some distance from the riometer sites (see Table 2) and that the relationship between electron-flux at geostationary orbit and riometer data from the dayside ionosphere is complex. Baker et al. (1981) demonstrated that the flux-absorption relationship is heavily dependent on the strength of the pitchangle diffusion, even when the flux is above the KennelPetschek limit. In addition the LANL satellites provide a snapshot of the flux in the radiation belts at geosynchronous orbit and so are not directly comparable (in time and structure) with measurements of CNA away from the footprint. 
For injection B LANL-01A was in the electron injection region at 05:40 UT, as evidenced by the dispersionless signature. 1990-095 was also in the injection region (Fig. 5) and showed similar timing of injection to LANL01A but with larger flux values; for example the flux of electrons between 75 and $105 \mathrm{keV}$ ranged from 5 to 15 times greater at 1990-095 than at LANL-01A. This is either a difference in the nature of the injection region across MLT or else LANL-01A is connected to a different drift path than 1990-095 (Table 2 shows that the satellites are on different dipole L-shells). An analysis of the dispersed signature at LANL-02A places the eastern boundary of the injection at $\sim$ 07:00 MLT; therefore the Finnish riometers are close to the injection region $(\sim 08: 30$ MLT) but only the two lowest latitude instruments (Oulu and Jyväskylä) observe absorption enhancements with a response at 05:55 UT. The lack of CNA at the time of the injection is likely related to the low electron flux observed at LANL-01A ( $1 \mathrm{~h}$ of MLT west of the riometer site). In this case, although there is injection of electrons across a wide range of MLT as indicated by the geosynchronous satellites the precipitation region is narrower, confined to the more westward portion of the injection region over Canada. The flux continues to increase at LANL-01A such that by 06:00 UT the levels are comparable with those at 1990-095 at the time of the injection. With no direct measurement of the injection region available at lower latitudes it is difficult to be certain of the cause of the delayed response at Oulu and Jyväskylä, however a slow response is expected at lower latitudes where the drift speed is lower than at higher L-shells. It is not until 06:24 UT (almost an hour after injection) that Kilpisjärvi records a response; this is an isolated increase $(\sim 1 \mathrm{~dB})$ followed by some weaker structure $<0.8 \mathrm{~dB}$. The increased absorption south of Ivalo (maximum at Rovaniemi and extending beyond Oulu) occurs at a similar time to the drift echo in the LANL-01A data, which has raised the total flux $(50-315 \mathrm{keV})$ by a factor of 3 to $1.8 \times 10^{6}$ electrons $\mathrm{cm}^{-2} \mathrm{~s}^{-1} \mathrm{sr}^{-1} \mathrm{keV}^{-1}$ since 06:00 UT. Of course the LANL satellites are separated from the Lshell of Rovaniemi by $\sim 1.6 R_{E}$ and the weaker response at Kilpisjärvi $\left(\Delta \mathrm{L} \sim 0.5 R_{E}\right)$ suggests that the electron flux is somewhat higher at $\mathrm{L}=5$ than at geostationary orbit. Jelly and Brice (1967) found that the fluxes of electrons in the inner magnetosphere following periods of low geomagnetic activity $(\sim 12 \mathrm{~h})$ were insufficient to produce dayside precipitation even after injections from small substorms. It seems that the same effect can be produced during periods of sustained activity such as this sawtooth event (average $K_{p}=6$ since the CME impacts on 17 April 2002) when the loss of electrons is increased and precipitation is only triggered once continuous (or secondary) injections have raised the electron flux on a given drift shell beyond the stable trapping limit (Kennel and Petshcek, 1966).
The rise-time of absorption when compared to the electron flux signatures at the LANL spacecraft suggests that it is most associated with electrons of energy in excess of $100 \mathrm{keV}$. The flux of $105-150 \mathrm{keV}$ electrons surpassed $4 \times 10^{4} \mathrm{~cm}^{-2} \mathrm{~s}^{-1} \mathrm{sr}^{-1} \mathrm{keV}^{-1}$ shortly before the absorption increase (at Rovaniemi) peaking at 06:53 UT at $1.1 \times 10^{5} \mathrm{~cm}^{-2} \mathrm{~s}^{-1} \mathrm{sr}^{-1} \mathrm{keV}^{-1}$. The peak flux levels at LANL-01A during injection A2 are of similar values to this peak and notably Kilpisjärvi responded to A2 but not B. According to Kennel and Petschek (1966) the stably trapped limit (for electrons $>40 \mathrm{keV}$ ) increases as the particles approach noon, thus a higher particle flux is required to initiate precipitation.

The final injection, $\mathrm{C}$, was heavily confined to the duskmidnight sector. The $50-75 \mathrm{keV}$ electron flux at LANL$01 \mathrm{~A}$ rises by a factor of 4 (to $7 \times 10^{5} \mathrm{~cm}^{-2} \mathrm{~s}^{-1} \mathrm{sr}^{-1} \mathrm{keV}^{-1}$ ) between 08:55 and 09:08 UT. Since absorption increases at 09:05 UT this suggests that the injection at 08:12 UT was sufficient to instigate precipitation at the SGO riometers on the dayside and the CNA is predominantly caused by electrons greater than $50 \mathrm{keV}$. The timing of the onset at Gillam and Ivalo is most likely coincidental since the electron flux on the relevant drift path for Gillam only reached the critical level following the secondary injection at 08:31 UT. Therefore it seems that the electron flux at lower $\mathrm{L}$ shells $(\mathrm{L}<5.7)$ is high enough to trigger precipitation. The lack of a response at Kilpisjärvi is indicative of the lower fluxes at higher L-shells over Finland: for the lowest energy channel compare $7 \times 10^{5} \mathrm{~cm}^{-2} \mathrm{~s}^{-1} \mathrm{sr}^{-1} \mathrm{keV}^{-1}$ at LANL-01A with $5 \times 10^{6} \mathrm{~cm}^{-2} \mathrm{~s}^{-1} \mathrm{sr}^{-1} \mathrm{keV}^{-1}$ at 1991-080; the pre 08:31 UT flux level at 1991-080 is more comparable $\left(2 \times 10^{5} \mathrm{~cm}^{-2} \mathrm{~s}^{-1} \mathrm{sr}^{-1} \mathrm{keV}^{-1}\right)$.

Thus higher absorption is confined to the ionosphere that is linked to regions of the inner magnetosphere. Consequently, it can be inferred that electron fluxes remain high at lower latitudes $(\mathrm{L}<5)$, possibly aided by radial diffusion over the preceding hours. At higher latitudes many of the drifting electrons are being lost, probably through a mixture of precipitation between Canada and Europe and the open drift paths of some of the electrons, carrying them to the magnetopause.

\section{Summary and conclusions}

Observations of CNA during a quasi-periodic sawtooth event have been presented for the first time. Data have been used from an extensive network of riometers (GLORIA) that covers the Canadian and northern European sectors. Night side observations during the first four injections show that the sawtooth event is consistent with the expected precipitation pattern from a series of quasi-periodic substorms. For the first two injections L-shell dispersion of CNA was observed on the dayside, consistent with the effects of gradientcurvature drift; this effect disappears such that gradientcurvature drift is no longer the dominant mechanism in 
determining the apparent absorption motion. Following the latter two injections CNA is not observed until over an hour later; this is likely caused by the drifting electron flux being below the stable-trapping limit; continuous or secondary injections add more electrons onto the drift shells such that the electron flux is increased sufficiently to produce precipitation on the drift echo.

Following the third injection a case of westward moving absorption in the pre-midnight sector has been identified. Although this motion is matched by the lower energy precipitation recorded by FUV the speed of motion rules out $\boldsymbol{E} \times \boldsymbol{B}$ drift as the mechanism. Instead we suggest that it is an azimuthal expansion of the injection region such that the precipitation trigger is moving westward and the motion of the electrons in the magnetosphere is still eastward. This may explain other instances of westward motion that have been identified by past authors in the global pattern of absorption motion.

Observations of CNA following the fourth injection show that the azimuthal motion of absorption across a relatively large base line varies in speed (in this case it accelerates). This may be caused either by a change in the dominant energy of precipitation related to the particles that are being continually injected from the magnetotail or through acceleration of the electron population in the duskward convection electric field. It is impossible to be certain without direct measurements of the precipitation spectrum even though it does reinforce past observations of hardening spectra on the dayside as absorption events progressed. Therefore large uncertainties and errors will arise when widely spaced riometers are used to estimate the energy or drift speed of the electron population that contributes to the precipitation.

Finally, an important point relating to the sawtooth injections should be considered. The first two injections are separated by $\sim 40 \mathrm{~min}$ rather than the $2-4 \mathrm{~h}$ that usually characterise the sawtooth injections, although this may be an example of a single complex response to the continuing energy input to the magnetosphere within the quasi-periodicity. Each signature in the LANL data is accompanied by a dipolarization in at least one of the GOES satellites and has corresponding ground signatures suggestive of possible substorm activity. It appears that the growth phase is continuing away from and after the initial onset resulting in an expansion. The short time separation may be due to triggering by variable solar wind conditions (IMF $B_{Y}$ and dynamic pressure) before it settled into the more stable configuration that accompanied the remainder of the injections.

Acknowledgements. The CANOPUS instrument array was constructed, maintained and operated by the Canadian Space Agency, and provided riometer, magnetometer and optical data for this study. The Imaging Riometer for Ionospheric Studies (IRIS) is operated by the Department of Communication Systems at Lancaster University (UK) in collaboration with the Sodankylä Geophysical Observatory and funded by the Particle Physics and Astronomy Research Council (PPARC). Thanks to S. R. Marple and E. Spanswick for process- ing the IRIS and CANOPUS riometer data, respectively. We are grateful to H. Singer and the Space Environment Center for supplying the GOES data via CDAWeb. ACE data were provided via OMNIWeb. IMAGE FUV analysis is supported by NASA through Southwest Research Institute subcontract number 83820 at the University of California, Berkeley, contract NAS5-96020. G. Lu was supported by NASA SEC theory and Guest Investigator programs. A. J. Kavanagh is grateful to NSF/NCAR/HAO for support through a Postdoctoral fellowship from the HAO Visitors Committee.

Topical Editor I. A. Daglis thanks C. R. Clauer and another referee for their help in evaluating this paper.

\section{References}

Akasofu, S.-I.: Polar and Magnetospheric substorms, D. Reidel, Holland, 1968.

Aminaei, A., Honary, F., Kavanagh, A. J., Spanswick, E., and Viljanen, A.: Characteristics of night-time absorption spike events, Ann. Geophys., 24, 1887-1904, 2006, http://www.ann-geophys.net/24/1887/2006/.

Ansari, Z. A.: The aurorally associated absorption of cosmic noise at College Alaska, J. Geophys. Res., 69, 4493-4513, 1964.

Baker, D. N., Stauning, P., Hones, E. W., Higbie, P. R., and Belian, R. D.: Near equatorial high resolution measurements of electron precipitation at L $\approx 6.6$, J. Geophys. Res., 86, 2295-2313, 1981.

Baker, K. B. and Wing, S.: A new magnetic coordinate system for conjugate studies at high latitudes, J. Geophys. Res., 94, 91399143, 1989.

Belian R. D., Cayton, T. E., and Reeves, G. D.: Quasi-periodic global substorm generated flux variations observed at geosynchronous orbit, in: Space Plasma: Coupling between small and medium scale processes, Geophys. Monogr. Ser., 86, edited by: Ashour-abdalla, M., Chang, T., and Dusenbery, P., 143-148, AGU, 1995.

Borovsky, J., Nemzek, R. J., and Belian, R. D.: The occurrence rate of magnetospheric-substorm onsets: Random and periodic substorms, J. Geophys. Res., 98, 3807-3813, 1993.

Borovsky, J. E., Thomsen, M. F., Reeves, G. D., Liemohn, M. W., Kozyra, J. U., Clauer, R., and Singer, H. J.: Global sawtooth oscillations of the magnetosphere during large storms, EOS Trans. Amer. Geophys. Soc., 82(47), F1077, 2001.

Browne, S., Hargreaves, J. K., and Honary, B.: An Imaging Riometer for Ionospheric Studies, Elect. Comm. Eng. J., 7, 209-217, 1995.

Clauer, C., R., Cai, X., Welling, D., DeJong, A., and Henderson, M. G.: Characterising the 18 April 2002 storm-time sawtooth events using ground magnetometer data, J. Geophys. Res., 111, A04S90, doi:10.1029/2005JA011099, 2006.

Coroniti, F. V. and Kennel, C. F.: Electron Precipitation Pulsations, J. Geophys. Res., 75, 1279-1289, 1970.

Frey, H. U., Mende, S. B., Immel, T. J., Gerard, J.-C., Hubert, B., Habraken, S., Spann, J., Gladstone, G. R., Bisikalo, D. V., and Shematovich, V. I.: Summary of quantitative interpretation of IMAGE far ultraviolet auroral data, Space Sci. Rev., 109(1), 255-283, 2003.

Hargreaves, J. K.: On the variation of auroral radio absorption with geomagnetic activity, Planet. Space. Sci., 14, 991-1006, 1966.

Hargreaves, J. K.: Auroral Motions Observed with Riometers: Latitudinal Movements and a Median Global Pattern, J. Atmos. Terr. 
Phys., 30, 1461-1470, 1968.

Hargreaves, J. K.: Auroral Absorption of HF Radio Waves in the Ionosphere: A Review of Results from the First Decade of Riometry, Proc. IEEE, 57, 1348-1373, 1969.

Hargreaves, J. K.: Dynamics of Auroral Absorption in the Midnight Sector - The Movement of Absorption Peaks in Relation to the Substorm Onset, Planet. Space Sci., 22, 1427-1441, 1974.

Hargreaves, J. K., Browne, S., Ranta, H., Ranta, A., Rosenberg, T. J., and Detrick, D. L.: A study of substorm associated nightside spike events in auroral absorption using imaging riometers at South Pole and Kilpisjärvi, J. Atmos., Sol. Terr. Phys., 59, 853-872, 1997.

Hargreaves, J. K., Chivers, H. J. A., and Axford, W. J.: Development of substorm in auroral radio absorption, Planet Space Sci., 23, 905-911, 1975.

Hargreaves, J. K. and Berry, M. G.: The eastward movement of the structure of auroral radio absorption events in the morning sector, Ann. Geophys., 32, 401-406, 1976, http://www.ann-geophys.net/32/401/1976/

Hargreaves, J. K. and Devlin, T.: Morning Sector electron precipitation events observed by incoherent scatter radar, J. Atmos. Terr. Phys., 52, 193-203, 1990.

Hargreaves, J. K., Ranta, A., Annan, J. D., and Hargreaves, J. C.: Temporal Fine Structure of nighttime spike events in auroral radio absorption, studied by wavelet method., J. Geophys. Res., 106, 24 621-24 636, 2001.

Henderson, M. G.: The May 2-3 1986 CDAW-9C interval: A sawtooth event, Geophys. Res. Lett., 31, L11804, doi:10.1029/2004GL019941, 2004

Henderson, M. G., Reeves, G. D., Skoug, R., Thomsen, M. F., Denton, M. H., Mende, S. B., Immel, T. J., Brandt, P. C., and Singer, H. J.: Magnetospheric and auroral activity during the 18 April 2002 sawtooth event, J. Geophys. Res., 111, A01S90, doi:10.1029/2005JA011111, 2006.

Henderson, M. G., Friedel, R. H., Skoug, R. M., Jahn, J. M., Mende, S. B., Immel, T. J., Ingraham, J., Cayton, T. E., and Thomsen, M. F.: Simultaneous multipoint Observations of stormtime substorms with the CLUSTER, IMAGE, POLAR, geosynchronous and GPS satellites, EOS Trans. Amer. Geophys. Soc., 83(19), S287, 2002

Huang, C.-S., Reeves, G. D., Borovsky, J. E., Skoug, R. M., Pu, Z. Y., and Le, G.: Periodic magnetospheric substorms and their relationship with solar wind variations, J. Geophys. Res., 108, 1255, doi:10.1029/2002JA009704, $2003 \mathrm{a}$.

Huang, C.-S., Foster, J. C., Reeves, G. D., Le, G., Frey, H. U., Pollock, C. J., and Jahn, J.-M.: Periodic magnetospheric substorms: Multiple space-based and ground-based instrumental observations, J. Geophys. Res., 108, 1411, doi:10.1029/2003JA009992, 2003 b.

Immel, T. J., Craven, J. D., and Nicholas, A. C.: An empirical model of the OI FUV dayglow from DE-1 images, J. Atmos. Solar. Terr. Phys., 62(1), 47-64, 2000.

Jelly, D. H.: On the morphology of auroral absorption during substorms, Can. J. Phys., 48, 335-345, 1970.

Jelly, D. H. and Brice, N. M.: Changes in van Allen radiation associated with polar substorms, J. Geophys. Res., 72, 5919-5931, 1967.

Jussila, J. R. T, Aikio, A. T., Shalimov, S., and Marple, S. R.: Cosmic radio noise absorption events associated with equatorward drifting arcs during a substorm growth phase, Ann. Geophys., 22, 1675-1686, 2004

http://www.ann-geophys.net/22/1675/2004/.

Kavanagh, A. J., Honary, F., McCrea, I. W., Donovan, E., Woodfield, E. E., Manninen, J., and Anderson, P. C.: Substorm related changes in precipitation in the dayside auroral zone - a multi instrument case study, Ann. Geophys., 20, 1321-1334, 2002, http://www.ann-geophys.net/20/1321/2002/.

Kavanagh, A. J., Kosch, M., Honary, F., Senior, A., Marple, S. R. Woodfield, E. E., and McCrea, I. W.: The statistical dependence of auroral absorption on geomagnetic and solar wind parameters, Ann. Geophys., 22, 877-887, 2004, http://www.ann-geophys.net/22/877/2004/.

Kennel, C. F. and Petschek, H. E.: Limit on stably trapped particle fluxes, J. Geophys. Res., 71, 1-28, 1966.

Kokubun, S., Yamamoto, T., Acuna, M. H., Hayashi, K., Shiokawa, K., and Kawano, H.: The Geotail Magnetic Field Experiment, J. Geomag. Geoelectr., 46, 7-21, 1994.

Koskinen, H. E. J., Lopez, R. E., Pellinen, R. J., Pulkkinen, T. I., Baker, D. N., and Bösinger, T.: Pseudobreakup and substorm growth phase in the ionosphere and magnetosphere, J. Geophys. Res., 98, 5801-5814, 1993.

Little, C. G. and Leinbach, H.: The riometer: a device for the continuous measurements of Ionospheric absorption, Proc. IRE, 37, 315-320, 1959.

Lui, A. T. Y., Hori, T., Ohtani, S., Zhang, Y., Zhou, X. Y., Henderson, M. G., Mukai, T., Hayakawa, H., and Mende, S. B.: Magnetotail behaviour during storm time "sawtooth injections", J. Geophys. Res., 109, A10215, doi:10.1029/2004JA010543, 2004.

Mandea, M. and Macmillan, S.: International Geomagnetic Reference Field - the eighth generation, Earth, Planets and Space, 52, 1119-1124, 2000

Mende, S. B., Heetderks, H., Frey, H. U., Lampton, M., Geller, S P., Abiad, R., Siegmund, O., Tremsin, A. S., Spann, J., Dougani, H., Fuselier, S. A., Magoncelli, A. L., Bumala, M. B., Murphree, S., and Trondsen, T.: Far ultraviolet imaging from the IMAGE spacecraft: 2. Wideband FUV imaging, Space Sci. Rev., 91, 271285, 2000.

McComas, D. J., Bame, S. J., Barker, P., Feldman, W. C., Phillips, J. L., Riley, P., and Griffee, J. W.: Solar Wind Electron Proton Alpha Monitor (SWEPAM) for the Advanced Composition Explorer, Space Sci. Rev., 86, 563-612, 1998.

Nielsen, E. and Axford, W. I.: Small-scale auroral absorption events associated with substorms, Nature, 267, 502-504, 1977.

Nishino, M., Nishitani, N., Sato, N., Yamagishi, H., Lester, M., and Holtet, J. A.: A Rectified Response of Daytime Radio Wave Absorption to Southward and Northward Excursions During Northward Interplanetary Magnetic Field: A Case Study, Adv. Polar Upper Atmos. Res., 13, 139-153, 1999.

Pellinen, R. J. and Heikkila, W. J.: Inductive electric fields in the magnetotail and their relation to auroral and substorm phenomena, Space Sci. Rev., 37, 1-61, 1984.

Pytte, T., Trefall, H., Kremser, L., Tankskanen P., and Riedler, W. On the morphology of energetic ( $>30 \mathrm{keV}$ ) electron precipitation at the onset of negative magnetic bays, J. Atmos. Terr. Phys., 38 , 757-774, 1976.

Ranta, H., Ranta, A., Collis, P. N., and Hargreaves. J. K.: Development of the Auroral Absorption Substorm: Studies of Pre-onset Phase and Sharp Onset Using an Extensive Riometer Network, 
Planet. Space Sci., 29, 1287-1313, 1981.

Ranta, H., Ranta, A., Collis, P. N., and Hargreaves, J. K.: SmallScale Structure of Ionospheric Absorption of Cosmic Noise During Pre-Onset and Sharp Onset Phases of an Auroral Absorption Substorm, Geophysica, 35, 45-57, 1999.

Reeves, G. D., Fritz, T. A., Cayton, T. E., and Belian, R. D.: Multisatellite measurements of the substorm injection region, Geophys. Res. Lett., 17, 2015-2018, 1990.

Reeves, G. D., Henderson, M. C., Skoug, R. M., Thomsen, M. F., Borovsky, J. E., Funsten, H. O., C:son Brandt, P., Mitchell, D. J., Jahn, J.-M., Pollock, J., McComas, D. J., and Mende, S. B.: IMAGE, POLAR, and geosynchronous observations of substorm and ring current ion injection, in Disturbances in Geospace: The Storm-Substorm Relationship, Geophys. Monogr. 142, AGU, 2003.

Richmond, A. D. and Kamide, Y.: Mapping electrodynamic features of the high-latitude ionosphere from localized observations: Technique, J. Geophys. Res., 93, 5741-5759, 1988.

Rostoker, G., Samson, J. C., Creutzberg, F., Hughes, T. J., McDiarmid, D. R., McNamara, A. G., Vallance Jones, A., Wallis, D. D., and Cogger, L. L.: CANOPUS - a ground-based instrument array for remote sensing the high latitude ionosphere during the ISTP/GGS program, Space Sci. Rev., 71 , 743-760, 1995.

Russell, C. T.: Geophysical coordinate transformations, Cosmic Electrodynamics, 2, 184-196, 1971.

Senior, A. and Honary, F.: Observations of the spatial structure of electron precipitation pulsations using an imaging riometer, Ann. Geophys., 21, 997-1003, 2003,

http://www.ann-geophys.net/21/997/2003/.
Singer, H. J., Matheson, L., Grubb, R., Newman, A., and Bouwer, S. D.: Monitoring Space Weather with the GOES Magnetometers. /SPIE Conference Proceedings, edited by: Washwell, E. R., 2812, 299-308, GOES-8 and Beyond, 1996.

Skoug, R. M., Thomsen, M. F., Reeves, G. D., Borovsky, J. E., Henderson, M. G., Funsten, H. O., Pollock, C.J., McComas, D. J., Jahn, J. M., Brandt, P. C., Mitchell, D. G., Singer H. J., and Mende, S. B.: Stormtime sawtooth flux variations., EOS Trans. Amer. Geophys. Soc., 83(19), S299, 2002.

Smith, C. W., L'Hereux, J., Ness, N. F., Acuna, M. H., Burlaga, L. F., and Schiefle, J.: The ACE Magnetic Fields Experiment, Space Sci. Rev., 86, 613-632, 1998.

Spanswick, E., Donovan, E., Liu, W., Wallis, D., Aasnes, A., Hiebert, T., Jackel, B., Henderson, M., and Frey, H.: Substorm Associated Spikes in High Energy Particle Precipitation, in The Inner Magnetosphere: physics and Modelling, AGU Geophys. Monogr. Series, 155, 227-236, 2005.

Stauning, P.: High-latitude D- and E-region investigations using imaging riometer observations, J. Atmos. Terr. Phys., 58, 765783, 1996.

Thomsen, M. F., Birn, J., Borovsky, J. E., Morzinski, K., McComas, D. J., and Reeves, G. D.: Two-satellite observations of substorm injections at geosynchronous orbit, J. Geophys. Res., 106, 84058416, 2001.

Weimer, D. R., Ober, D. M., Maynard, N. C., Collier, M. R., McComas, D. J., Ness, N. F., Smith, C. W., and Watermann, J.: Predicting interplanetary magnetic field (IMF) propagation delay times using the minimum variance delay technique, J. Geophys. Res., 108(A1), 1026, doi:10.1029/2002JA009405, 2003. 